\title{
Toxicological Evaluation of Saposhnikoviae Radix Water Extract and its Antihyperuricemic Potential
}

\author{
Chang Won Kim', Jae Hyuck Sung ${ }^{2}$, Jeong Eun Kwon', Hyeon Yeol Ryu'², Kyung Seuk Song ${ }^{2}$, \\ Jin Kyu Lee', Sung Ryul Lee ${ }^{3}$ and Se Chan Kang' \\ ${ }^{1}$ Department of Oriental Medicine and Biotechnology, Kyung Hee University, Yongin, Korea \\ ${ }^{2}$ Korea Conformity Laboratories, Incheon, Korea \\ ${ }^{3}$ Department of Integrated Biomedical Science, Cardiovascular and Metabolic Disease Center, College of Medicine, \\ Inje University, Busan, Korea
}

\begin{abstract}
Although the dried root of Saposhnikovia divaricata (Turcz.) Schischk. (Umbelliferae) is a popular medicinal plant in East Asia, there has been no systemic toxicological evaluation of a water extract of Saposhnikoviae Radix (SRE). In this experiment, an oral acute and 13-week subchronic toxicological evaluations of SRE (500-5,000 mg/ $\mathrm{kg}$ body weight) were performed in both sexes of $\mathrm{Crl}: \mathrm{CD}(\mathrm{SD})$ rats. Based on the results from mortality, clinical signs, effects on body weight and organ weight, clinical biochemistry, hematology, urinalysis, and histopathology, significant acute, 4-week repeated dose range finding (DRF) and 13-week subchronic toxicity of SRE was not observed in either sex of rats; thus, the no observed adverse effect level (NOAEL) was 5,000 mg (kg/day). To identify anti-hyperuricemia potential of SRE, the suppressive effect of SRE was determined in mice challenged with potassium oxonate (PO; $250 \mathrm{mg} / \mathrm{kg}$ ) via intraperitoneal injection for 8 days (each group; $\mathrm{n}=7$ ). SRE supplementation suppressed the uric acid level in urine through significant xanthine oxidase (XO) inhibitory activity. Kidney dysfunctions were observed in PO-challenged mice as evidenced by an increase in serum creatinine level. Whereas, SRE supplementation suppressed it in a dose-dependent manner. Collectively, SRE was safe up to $5,000 \mathrm{mg}$ (kg/day) based on NOAEL found from acute and 13-week subchronic toxicological evaluations. SRE had anti-hyperuricemia effect and lowered the excessive level of uric acid, a potential factor for gout and kidney failure.
\end{abstract}

Key words: Saposhnikoviae radix, 13-week repeated toxicity, NOAEL, Potassium oxonate, Anti-hyperuricemia, Extract

\section{INTRODUCTION}

Traditional herbal medicines are naturally occurring, plant-derived substances with minimal or no industrial processing, and have been historically used to treat illnesses in local or regional healing practices (1). The word "traditional" means that the herbal product is intended and

Correspondence to: Se Chan Kang, Department of Oriental Medicine and Biotechnology, Kyung Hee University, 1732 Deogyeong-daero, Giheung-gu, Yongin-si, Gyeonggi-do 17104, Korea E-mail: sckang@khu.ac.kr

This is an Open-Access article distributed under the terms of the Creative Commons Attribution Non-Commercial License (http:// creativecommons.org/licenses/by-nc/3.0) which permits unrestricted non-commercial use, distribution, and reproduction in any medium, provided the original work is properly cited. designed for administration via the oral route without intervention from a registered medical practitioner for diagnosis, monitoring, or treatment (2). Saposhnikoviae Radix (Bang Fung in Korean; Fang-Feng in Chinese; siler in English) is a dried root from the perennial herb Saposhnikovia divaricate (Turcz.) Schischk. of the family Umbelliferae. It has been widely used as a traditional medicine

Abbreviations: DRF, dose range finding; GLP, good laboratory practice; HPLC, high performance liquid chromatography; ITS, internal transcribed spacer; NOAEL, no observed adverse effect level; OECD, the organization for economic cooperation and development; SD, Crl:CD; SOPs, standard operation procedures; UA, uric acid; URAT1, protein transporter of urate; $\mathrm{XO}$, xanthine oxidase. 
for alleviating inflammation, rheumatic conditions, spasms, and other ailments in East Asia (3-7). Numerous active compounds with pharmaceutical potential have been identified in Saposhnikoviae Radix, including chromones (prim-O-glucosylcimifugin, 4'-O- $\beta$-d-glucosyl-5-O-methylvisamminol, 3'-O-angeloylhamaudol, sec-O-glucosylhamaudol, and cimifugin), and coumarins (nodakenin, psoralen, bergapten, imperatorin, phellopterin, and anomalin), among others $(4,8,9)$. Coumarins represent a substantial class of condensed heterocycles that manifest a miscellanea of significant biological activities, including anti-inflammatory (10), antioxidant, anti-adipogenic, anticancer, antiviral, anticoagulant, and neuroprotective properties (11). Saposhnikoviae Radix contains several chromones and a variety of coumarins, including nodakenin, anomalin, diphenols, acid esters, and polyacetylene, among others (3). Nodakenin has been widely used as a marker compound for the separation of constituents from the Saposhnikoviae Radix extract $(9,12,13)$.

In addition to easy access, therapeutic efficacy, and relatively low cost of traditional medicines, ultimately, safety concerns are most important in order to adapt existing treatments for clinical use and to develop new products. It is believed that Saposhnikoviae Radix, the dried root of Saposhnikovia divaricata (Turcz.) Schischk. (Umbelliferae), is a top-grade source of herbal medicine, though its toxicity is not well established $(14,15)$. In this research, the toxicity of a water extract of Saposhnikoviae Radix (SRE) was determined by assessing single-dose toxicity, subchronic 4-week repeated-dose range finding (DRF) toxicity, and chronic 13-week subchronic toxicity in male and female Crl:CD (SD) rats. In addition, we tested the temporal stability of SRE depending on storage temperature $\left(4^{\circ} \mathrm{C}\right.$ or room temperature) for up to one year, because the amounts of active compounds in herbal medicines can be altered by storage conditions, which can decrease their therapeutic efficacy (16).

There is an increasing trend in the prevalence of hyperuricemia and gout in the Western world. In fact, a number of population-based studies estimate a prevalence of up to $21 \%$ for hyperuricemia and $1-4 \%$ for gout (17). Uric acid (UA) is a metabolite obtained from purine by the activity of xanthine oxidase (XO), and high levels of serum UA lead to hyperuricemia and gout. Although allopurinol, a $\mathrm{XO}$ inhibitor, and benzbromarone, an inhibitor of protein transporter of urate (URAT1) are considered safe first-line drugs in gout, side effects such as liver toxicity, gastrointestinal disorders, and skin rash can occur (17). To describe the potential of SRE against hyperuricemia, the effect of SRE on serum UA, serum creatine, urinary UA, and urinary $\mathrm{XO}$ activity were determined in potassium oxonate (PO)-induced gout mice $(18,19)$. In addition, the histological evaluation of the kidney was conducted to identify the beneficial role of SRE on PO-induced kidney injury in mice.

\section{MATERIALS AND METHODS}

Study guidelines. Animal experiments were approved by the animal care and use committee at the Korea conformity laboratory (GT15-00418). All experiments were designed and conducted under the Organization for Economic Cooperation and Development (OECD) test guidelines No. 413, Good Laboratory Practice (GLP), and the Korean Ministry of Food and Drug Safety (KMFDS) Notice No. 2013-121 (Toxicity test standards of medicine and medical supplies). Although this study was not conducted under Good Laboratory Practice (GLP) regulations, general procedures in this study were performed according to the standard operation procedures (SOPs) of the GLP compliance testing facility.

Chemicals and reagents. Methanol, water, and acetonitrile of high-performance liquid chromatography (HPLC) grade were obtained from Honeywell Burdick \& Jackson (Morris Plains, NJ, USA). Trifluoroacetic acid, oxonic acid potassium salt (potassium oxonate), allopurinol, benzbromarone, and an XO activity assay kit were purchased from Sigma-Aldrich (St. Louis, MO, USA). Nodakenin (CAS Number 495-31-8) was purchased from ChemFaces (Wuhan, Hubei, China). A UA assay kit was obtained from YD Diagnostics (Yongin, Korea).

\section{Phylogenetic analysis of Saposhnikoviae Radix.} Saposhnikoviae Radix was obtained from the Kyungdong Yangnyeong-si market (Seoul, Korea). The specimen was scrutinized by Professor Se Chan Kang (Kyung Hee University, Yongin, Korea). A voucher specimen of the plant material was deposited at the Kyung Hee University of Oriental Medicine Biotechnology (Yongin, Korea). Due to morphological similarities when dried, the authenticity of Saposhnikoviae Radix was determined by phylogenetic analysis based on internal transcribed spacer (ITS) sequence alignment and genetic analysis. Briefly, total DNA extraction was achieved using a HiYield ${ }^{\mathrm{TM}}$ Genomic DNA Mini Kit (RBC Bioscience Co., Taipei, Taiwan). The primers used for regions and the PCR conditions were as follows: ITS2: S2F, ATGCGATACTTGGTGTGAAT; S3R, GACGCTTCTCCAGACTACAAT; PCR conditions: $94^{\circ} \mathrm{C}$ for $5 \mathrm{~min}$; 40 cycles at $94^{\circ} \mathrm{C}$ for $30 \mathrm{sec}, 56^{\circ} \mathrm{C}$ for $30 \mathrm{sec}$, and $72^{\circ} \mathrm{C}$ for $45 \mathrm{sec}$; and $72^{\circ} \mathrm{C}$ for $10 \mathrm{~min}$. An ABI Prism 3730xl DNA sequencer (Applied Biosystems, Foster City, CA, USA) was used to trim and assemble raw trace files. A BLAST analysis was performed using the nucleotide database at the National Center for Biotechnology Information (NCBI). Intra- and inter-species genetic distances were obtained with the Kimura-2-parameter (K2P) model of MEGA 6.00 (20). Intra- and inter-species pairwise divergences were 
calculated as a barcoding gap using TAXON DNA (21). A neighbor-joining tree based on the phylogenetic analysis was constructed with 1000 replicate bootstrap tests in order to identify Saposhnikoviae Radix via MEGA 6.0. (20).

\section{Preparation of the water extract of Saposhnikoviae}

Radix. Saposhnikoviae Radix (500 g) was selected based on $100 \%$ phylogenetic similarity and was subjected to hot water extraction for $4 \mathrm{hr}$. The water extract of Saposhnikoviae Radix (SRE) was prepared after the filtration with Whatman Qualitative No. 1 filter paper and subsequent concentration by a rotary evaporator (Eyela, Tokyo, Japan) at $40^{\circ} \mathrm{C}$. Water for oral delivery (lot L4P4K21, Dae Han Pharm. Co., LTD, Seoul, Korea) was used as a vehicle and negative control. The SRE suspension was prepared once per day and mixed just prior to each administration.

High-performance liquid chromatogram (HPLC). Nodakenin $\left(\mathrm{C}_{20} \mathrm{H}_{24} \mathrm{O}_{9}\right)$ is one of the coumarins identified in Saposhnikoviae Radix $(9,22)$. In addition to the phylogenetic analysis, an HPLC analysis was performed using nodakenin as a reference compound for determining the authenticity of Saposhnikoviae Radix. Nodakenin (500 $\mu \mathrm{g} / \mathrm{mL}$ ) was solubilized in methanol and serially diluted to 50,5 , and $0.5 \mu \mathrm{g} / \mathrm{mL}$ solutions. After the filtration, the SRE was solubilized in water $(250 \mathrm{mg} / \mathrm{mL})$ and was further diluted to concentrations of 10 and $1 \mathrm{mg} / \mathrm{mL}$ with methanol. The SHIMADZU LC 20AD HPLC system (Kyoto, Japan) was used with a PDA detector set at 335 nm. An ACE $\mathrm{C}_{18}$ column was used $(250 \mathrm{~mm} \times 4.6 \mathrm{~mm}$, $5 \mu \mathrm{M})$ at a temperature of $40^{\circ} \mathrm{C}$. The nodakenin content in the SRE was analyzed by HPLC using the protocol of Seo and Shin with slight modifications (23). The gradient eluted consisted of water with $0.1 \%$ trifluoroacetic acid (A) and acetonitrile with $0.1 \%$ trifluoroacetic acid (B). The mobile phase was used under binary linear gradient conditions as follows: $0-15 \mathrm{~min}, 10-60 \% \mathrm{~B} ; 15-20 \mathrm{~min}$, $60-100 \%$ B; $20-23 \mathrm{~min} .100 \%$ B; $23-25 \mathrm{~min}, 100-10 \% \mathrm{~B}$; $25-30 \mathrm{~min}, 10 \% \mathrm{~B}$. The flow rate was $1.0 \mathrm{~mL} / \mathrm{min}$, and the injection volume was $10 \mu \mathrm{L}$. Peaks were identified by comparing their retention times and UV-vis spectra with the nodakenin reference; data from three independent experiments were quantified using the corresponding curve of nodakenin.

Handling and care of experimental animals. 5Week-old male and female Crl:CD (SD) rats were obtained from Orient Bio Inc (Seongnam, Korea). Female rats were nulliparous and non-pregnant. Male ICR mice were obtained from Raonbio Co., Ltd (Yongin, Korea). The animals were housed individually in suspended, stainless-steel cages in an animal room at $23.1 \pm 0.6^{\circ} \mathrm{C}$, relative humidity of $57.5 \pm 3.6 \%$, and air ventilation of $10-15 \mathrm{times} / \mathrm{hr}$ (all-fresh ventilation) under illumination for a $12 \mathrm{hr}$ day (from $8 \mathrm{am}$ to $8 \mathrm{pm}$ ). The rats and mice had free access to commercial food pellets and clean drinking water. Instead of $2,000 \mathrm{mg} / \mathrm{kg} / \mathrm{day}$, which is the generally accepted maximal dose in toxicological evaluations, the maximal dose of SRE was set at $5,000 \mathrm{mg} / \mathrm{kg} /$ day to strengthen the confidence of the toxicological evaluation. The SD rats were used in the single-dose, 4-week repeated-dose, and the 13week subchronic oral toxicity tests, whereas the ICR mice were used in the PO-mediated gout model. Clinical signs and general appearance were observed once a week, and body weight and food consumption were also measured once a week. There was no treatment-related mortality during the experiment at any given dose. Blood samples were collected from the abdominal aorta under light ether anesthesia. Finally, a necropsy was performed at the end of the experiment.

Oral single-dose toxicity test. In the single-dose toxicity test, male and female SD rats were administered either vehicle or $5,000 \mathrm{mg} \mathrm{SRE} / \mathrm{kg}$ via the oral gavage method (each group, $n=5$ ). Each animal was observed for mortality clinical signs and behavioral changes such as salivation, lethargy, diarrhea, tremors, and convulsions after the first half-hour, every hr for six hr, and once daily for 13 days. Individual animal weights were recorded at the acquisition, grouping, immediately before administration, once a week during the study, and immediately before necropsy. The ocular fundus of all males and females was examined shortly before the scheduled termination using an indirect binocular ophthalmoscope (IO-H, Neitz Instruments Co., Japan). On day 13, surviving animals were anesthetized with $\mathrm{CO}_{2}$ inhalation, and the abdominal aorta and vena cava were severed. All animals were subjected to terminal necropsy at the end of the experiment, and vital organs were carefully observed macroscopically.

4-Week repeated-dose toxicity test. The 4-week repeated-dose toxicity (DRF) studies were conducted at doses of $0,500,1,000,2,500$, and 5,000 mg SRE/ $/ \mathrm{kg} /$ day via the oral gavage method. 5-Week-old-old male and female specific pathogen-free SD rats were acclimated for 5 days before the administration. When the rats were 6weeks old, they were exposed to SRE $(0,500,1,000$, 2,500 , or $5,000 \mathrm{mg} / \mathrm{kg} /$ day) by daily gavage for 28 days (each group, $\mathrm{n}=10$ ). Individual dosing volumes were calculated based on $10 \mathrm{~mL} / \mathrm{kg}$ of body weight as a dose volume. Control SD rats of both sexes (each sex, $n=10$ ) received the vehicle only at the same time and until the end of the experiment.

13-Week subchronic toxicity test. Based on the 4week DRF results, subchronic 13-week DRF studies of SRE were conducted with doses of 500, 1,000, 2,000, and $5,000 \mathrm{mg} \mathrm{SRE} / \mathrm{kg}$, with doses administered once daily by 
oral gavage in a dose volume of $10 \mathrm{~mL} / \mathrm{kg}$. 5-Week-old male and female specific pathogen-free SD rats were acclimated for 5 days before administration. During the study, body weight and food consumption rates were measured once a week. Cage site examinations were conducted daily, and mortality and clinical signs were recorded weekly.

Five groups of 10 males and 10 females were administered SRE once daily by oral gavage at doses of 0 (vehicle control), $500,1,000,2,000$, or $5,000 \mathrm{mg} / \mathrm{kg} /$ day in a dose volume of $10 \mathrm{~mL} / \mathrm{kg}$ for 13 weeks. Clinical signs and general appearances were observed once a week, and body weight and food consumption were measured once a week. A necropsy was performed at the end of the experiment.

Biochemical analysis. At the end of the experiment, blood was collected in plain tubes (for biochemistry) and EDTA-containing tubes (for complete blood count analysis) from the abdominal aorta and used for hematology, plasma coagulation, and blood biochemical tests. Urine samples were collected using metabolic cages for $24 \mathrm{hr}$. Through a necropsy, organ weights (testes, ovaries, uterus, prostate, spleen, liver, adrenal glands, kidneys, heart, lung, brain, pituitary, and thymus) were measured, and histopathological evaluations were conducted. Biochemical analysis and complete blood count from blood samples were performed using a Hitachi 7180 (Hitachi, Tokyo, Japan) and an automatic multichannel blood cell counter (ADVIA 2120, SIEMENS, Berlin, Germany), respectively.

Induction of hyperuricemia in mice and experimental protocol. The maximal treatment dose of SRE in mice was set at $500 \mathrm{mg} / \mathrm{kg}$, which showed a remarkable reduction in serum uric acid in male rats. Potassium oxonate was employed to induce gout mediated by the inhibition of uricase, according to a previous report (18). Here, we used male mice to investigate antihyperuricemia, because endogenous reproductive hormones during the menstrual cycle largely affect uric acid levels (24). Male mice were randomly assigned to one of seven groups $(\mathrm{n}=$ 7): (1) vehicle, (2) $\mathrm{PO}(250 \mathrm{mg} / \mathrm{kg})$, (3) $\mathrm{PO}+125 \mathrm{mg}$ $\mathrm{SRE} / \mathrm{kg}$, (4) PO + $250 \mathrm{mg} \mathrm{SRE} / \mathrm{kg}$, (5) PO + $500 \mathrm{mg} \mathrm{SRE} /$ $\mathrm{kg}$, (6) $\mathrm{PO}+$ allopurinol, and (7) PO + benzbromarone. Briefly, mice were intraperitoneally (i.p.) injected with $0.9 \% \mathrm{NaCl}$ in PBS containing PO $(250 \mathrm{mg} / \mathrm{kg}) 2 \mathrm{hr}$ before SRE, and allopurinol ( $5 \mathrm{mg} / \mathrm{kg}$ body weight), benzbromarone $(10 \mathrm{mg} / \mathrm{kg}$ body weight), or the vehicle was orally administered for 8 days. A necropsy was performed at the end of the experiment. Through necropsy, organ weights (liver, thymus, spleen, and kidneys) were measured, and histopathological evaluations were conducted. Blood samples were collected through the abdominal aorta. Blood samples were allowed to clot at room temperature $(25 \pm$ $2^{\circ} \mathrm{C}$ ) for $30 \mathrm{~min}$. Serum was separated via centrifuge at $3,500 \times g$ for $10 \mathrm{~min}$ at $4^{\circ} \mathrm{C}$, and creatinine level and xanthine oxidase activity in serum were measured using a commercial assay kit (25). Urine samples were collected using metabolic cages for $24 \mathrm{hr}$, and then UA level was determined using a UA assay kit (MyBioSource, SA, USA).

Histology. After euthanasia, kidney tissue was removed, fixed in $10 \%$ buffered formalin, and subjected to a routine histological process for paraffin embedding and light microscopic examination. Sections $(6-\mu \mathrm{m}$ thick) were stained with hematoxylin and eosin (H.E.). A blinded histological analysis was performed by a trained histologist.

Statistical analysis. Data are presented as mean \pm standard deviation (SD). Statistical analyses were performed using SPSS version 12.0 (IBM, Chicago, IL, USA). The differences between the vehicle control and the treated groups were analyzed through parametric or nonparametric multiple comparison procedures after one-way analysis of variance (ANOVA). If the variance was similar, Duncan's test was used, while if the variance was not similar, Dunnett's $t$-test was applied. Differences were determined to be statistically significant if $p<0.05$.

\section{RESULTS}

Phylogenetic confirmation of Saposhnikoviae Radix. The ambiguity of the origins of herbs makes them difficult to be utilized for clinical and industrial purposes (2). To confirm the originality of Saposhnikoviae Radix, a phylogenetic analysis based on the ITS alignment and genetic analysis of the ITS region was conducted. In the ITS2 regions, a total of 20 single-nucleotide polymorphisms were detected, and Saposhnikoviae Radix, Peucedani Radix, and Glehniae Radix were divided into different groups on a phylogenetic tree. Among the nine commercially available specimens, three specimens coincided $100 \%$ with Saposhnikovia divaricate (Turcz.), while others showed $95 \%(n=3)$ or $99 \%(n=3)$ coincidence (Fig. 1).

Determination of the stability of the SRE. The chemical stability of the extract is an important factor for the application for medicinal purposes (26) because low stability and/or degradation of the active compound can cause a reduction in its therapeutic efficacy. In addition, there is a possibility that an unintended transition to unrecognized derivatives could cause late toxicity. Thus, the stability of SRE was determined based on the changes in the content of nodakenin (Fig. 2), which is an active coumarin found in SRE (9), at $4^{\circ} \mathrm{C}$ and ambient room temperature for up to 12 months. As shown in Fig. 2, nodakenin in SRE stored at $4^{\circ} \mathrm{C}$ was highly preserved for up to 12 months, but SRE stored at ambient temperature 

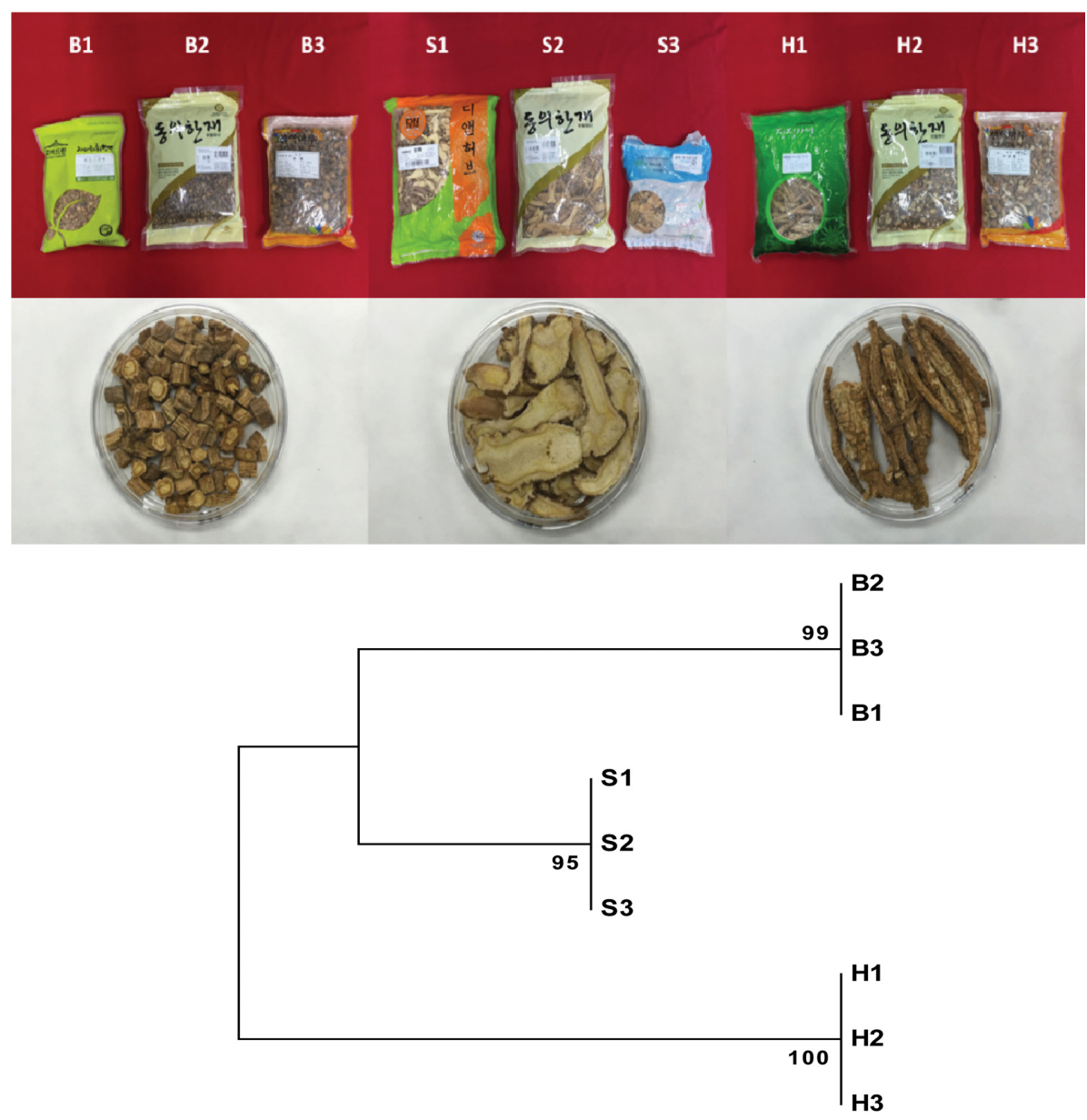

0.005

Fig. 1. Phylogenetic analysis of commercially available Radix Saposhnikoviae. Nine commercially available Saposhnikoviae Radix (B1-B3, S1-S3, and $\mathrm{H} 1-\mathrm{H} 3$ ) samples were purchased in Korea, and the authenticity of Saposhnikovia divaricate (Turxz.) was determined by phylogenetic analysis as described in Material and methods. $\mathrm{H} 1-\mathrm{H} 3$ show $100 \%$ similarity based on the Neighbor-Joining tree of cpDNA sequences of Saposhnikoviae species used in a subsequent experiment.

slightly degraded over time. Thus, SRE appears to be stable when stored at $4^{\circ} \mathrm{C}$ for up to 12 months without loss of its active component.

Acute toxicity of SRE. For determining the acute toxicity, a single-dose toxicity test of SRE was conducted at $5,000 \mathrm{mg} / \mathrm{kg}$ in male and female rats (each $\mathrm{n}=5$ ). No mortality and no notable clinical signs were observed in either the vehicle control or the $5,000 \mathrm{mg} \mathrm{SRE} / \mathrm{kg}$ group, including abnormal gait, dehydration, high or low posture, clear oral or nasal discharge, wet or stained fur, salivation, ataxia, or lethargy. There was no toxicologically significant difference in body weight changes (data not shown). At the necropsy, there were no gross findings in SRE-treated male or female rats compared to the control group. Based on these results, the approximate lethal dose
(ALD) of SRE is greater than $5,000 \mathrm{mg} / \mathrm{kg}$ body weight in rats.

Subchronic toxicity of SRE based on the 4-week repeated DRF study. During the 4-week repeated oral administration of SRE at $0,500,1,000,2,500$, or 5,000 $\mathrm{mg} / \mathrm{kg} /$ day (each group, $\mathrm{n}=10$ ), there were no significant differences in body weight between the control and SREtreated groups (data not shown). No adverse effects of SRE administration on mean food consumption were observed at any dose in males or females. No clinical signs of toxicity or mortality related to SRE administration were observed in the rats during the 4-week DRF period at any given dose. With respect to the ophthalmoscopy results, no abnormalities were detected at any dose in males or females. The weight of the lungs of the female 


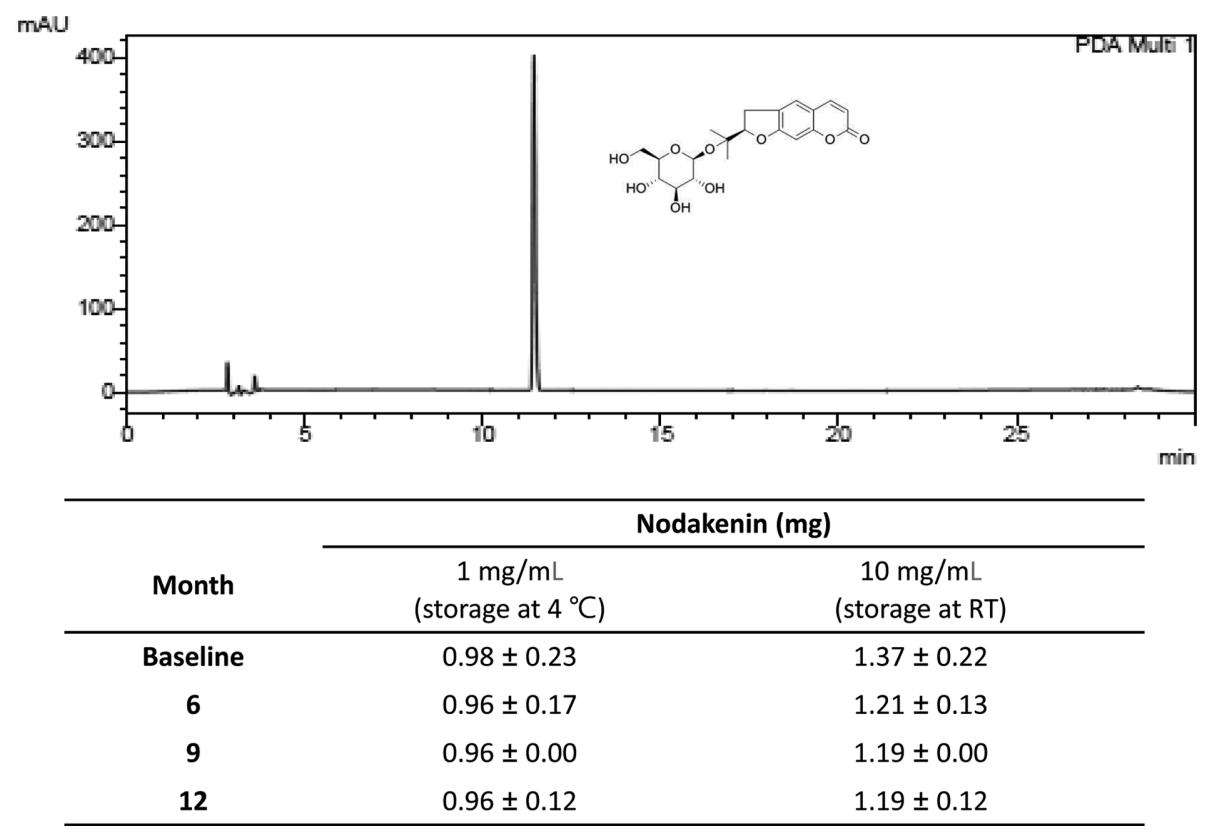

Fig. 2. Identification of nodakenin in SRE and its stability with temperature and time. Commercially available nodakenin was used as a standard. High-performance liquid chromatography (HPLC-PDA) chromatogram of nodakenin in SRE and its chemical structure (upper panel). The retention time of nodakenin was $11.4 \mathrm{~min}$. The contents of nodakenin in SRE were determined depending on storage temperature at $4^{\circ} \mathrm{C}$ and room temperature up to 12 months by HPLC (lower panel). Values are mean \pm SD. SRE, water extract of Radix Saposhnikoviae; RT, room temperature.

rats at 500 and $1,000 \mathrm{mg} \mathrm{SRE} / \mathrm{kg} /$ day and the thymus in female rats at $1,000 \mathrm{mg} \mathrm{SRE} / \mathrm{kg} /$ day were higher than that of the control group, but the difference was slight and was not observed in any other groups. Thus, these results are considered a result of biological variation. Regarding microscopic findings, cornified inflammatory cells were observed in adjacent adhesion sites of the spleen and adipose tissue in the female group of rats consuming $500 \mathrm{mg} \mathrm{SRE} / \mathrm{kg} /$ day. However, these findings might be associated with a single, accidental phenomenon. Infiltration of inflammatory cells and bronchial alveoli were observed in the lungs of the SRE-administrated groups to a mild or minimal degree. Slight hair loss was observed in 500 (1/10 males), 2,500 (1/10 males), and 5,000 (1/10 females) $\mathrm{mg} / \mathrm{kg} /$ day SRE-administrated rats, but this effect of SRE at the given doses might be considered a momentary occurrence because of its sporadicity. No other differences were observed between the control and SRE-administrated groups. Significant hematological differences were not identified in SRE-administrated groups, except for a slight increase in white blood cell (WBC) count and neutrophil percentage in males receiving 2,500 $\mathrm{mg} \mathrm{SRE} / \mathrm{kg} /$ day, percent of large unstained cells (LUP) in females receiving 2,500 mg SRE/ $\mathrm{kg} /$ day, percent of basophils (BAP) in females receiving $5,000 \mathrm{mg} \mathrm{SRE} / \mathrm{kg} /$ day, hematocrit of males receiving 2,500 $\mathrm{mg} \mathrm{SRE} / \mathrm{kg} / \mathrm{day}$, and both RDW and reticulocyte percentage in females receiving $500 \mathrm{mg} \mathrm{SRE} / \mathrm{kg} /$ day compared to the control group $(p<0.05)$. In a biochemical analysis in serum, there were no significant changes, except a decrease in the sodium $(\mathrm{Na})$ concentration in males consuming $1,250,2,500$, and $5,000 \mathrm{mg} \mathrm{SRE} / \mathrm{kg} /$ day $(p<0.01)$ and total bilirubin in females consuming $5,000 \mathrm{mg} \mathrm{SRE} / \mathrm{kg} /$ day $(p<0.05)$. Collectively, all of these results suggest that SRE up to $5,000 \mathrm{mg} / \mathrm{kg} /$ day does not cause toxicity in either male or female rats.

\section{Evaluating 13-week repeated toxicity of SRE.}

- Mortality, clinical signs, and effects on body weight:

No clinical signs of toxicity or mortality related to the SRE administration were observed in the rats during the 13 -week study at any dose. There were no significant changes in body weight between control and SRE-administrated groups in rats of both sexes (Table 1).

- Food consumption: There were no significant changes in food consumption between the control and the SREadministrated groups in the rats of both sexes (Table 2).

- Urine analysis: Urinalysis results are depicted in Table 3. There was no statistical significance when comparing vehicle control and SRE-treated groups using chisquare analysis.

- Clinical chemistry: There were no changes in clinical chemistry parameters indicative of SRE-related organ toxicity (Table 4). Statistically significant differences from respective sex-matched controls were observed for a num- 
Table 1. Body weight values in male and female rats during oral administration of SRE for 13 weeks

\begin{tabular}{|c|c|c|c|c|c|c|c|c|c|c|}
\hline \multirow{2}{*}{$\begin{array}{c}\text { Sex } \\
\begin{array}{c}\text { SRE dose } \\
(\mathrm{mg} / \mathrm{kg} / \text { day })\end{array}\end{array}$} & \multicolumn{5}{|c|}{ Male (each group, $n=10$ ) } & \multicolumn{5}{|c|}{ Female (each group, $\mathrm{n}=10$ ) } \\
\hline & 0 (control) & 500 & 1000 & 2000 & 5000 & 0 (control) & 500 & 1000 & 2000 & 5000 \\
\hline \multicolumn{11}{|l|}{ Body weight (g) } \\
\hline Week 0 & $191.47 \pm 4.31$ & $190.64 \pm 4.44$ & $193.06 \pm 4.15$ & $191.98 \pm 5.83$ & $192.61 \pm 4.46$ & $165.78 \pm 6.37$ & $165.24 \pm 8.48$ & $166.33 \pm 6.74$ & $166.22 \pm 5.30$ & $168.14 \pm 7.69$ \\
\hline Week 1 & $255.32 \pm 5.36$ & $255.02 \pm 7.02$ & $255.78 \pm 9.71$ & $252.88 \pm 10.37$ & $252.56 \pm 10.74$ & $193.36 \pm 9.93$ & $197.04 \pm 10.75$ & $190.94 \pm 8.88$ & $195.86 \pm 9.69$ & $196.60 \pm 10.49$ \\
\hline Week 2 & $309.07 \pm 11.69$ & $306.95 \pm 11.00$ & $306.26 \pm 13.18$ & $301.72 \pm 13.86$ & $300.62 \pm 18.04$ & $210.79 \pm 12.53$ & $219.60 \pm 16.61$ & $210.47 \pm 12.81$ & $217.38 \pm 13.38$ & $220.08 \pm 11.40$ \\
\hline Week 3 & $353.41 \pm 19.55$ & $348.79 \pm 14.90$ & $347.32 \pm 15.81$ & $341.74 \pm 20.00$ & $336.94 \pm 23.90$ & $224.74 \pm 16.26$ & $238.05 \pm 18.85$ & $227.59 \pm 15.82$ & $238.93 \pm 14.28$ & $236.98 \pm 14.66$ \\
\hline Week 4 & $393.07 \pm 23.47$ & $382.71 \pm 19.50$ & $386.25 \pm 20.91$ & $377.60 \pm 25.12$ & $372.85 \pm 32.24$ & $237.92 \pm 14.37$ & $253.23 \pm 19.02$ & $243.45 \pm 17.36$ & $252.34 \pm 15.63$ & $256.16 \pm 21.35$ \\
\hline Week 5 & $428.24 \pm 30.22$ & $412.50 \pm 24.45$ & $417.72 \pm 23.86$ & $404.45 \pm 29.36$ & $394.97 \pm 38.13$ & $252.48 \pm 12.71$ & $269.08 \pm 21.28$ & $259.20 \pm 16.86$ & $267.76 \pm 17.77$ & $271.27 \pm 27.01$ \\
\hline Week 6 & $461.97 \pm 35.03$ & $438.97 \pm 24.56$ & $445.18 \pm 27.15$ & $432.65 \pm 32.16$ & $422.16 \pm 46.53$ & $264.95 \pm 14.88$ & $280.34 \pm 23.79$ & $271.36 \pm 18.07$ & $279.61 \pm 21.00$ & $281.72 \pm 26.34$ \\
\hline Week 7 & $478.64 \pm 41.69$ & $458.66 \pm 23.18$ & $463.78 \pm 30.68$ & $452.68 \pm 35.69$ & $442.07 \pm 51.62$ & $268.83 \pm 17.06$ & $286.26 \pm 24.07$ & $275.24 \pm 18.10$ & $287.41 \pm 19.36$ & $287.62 \pm 28.15$ \\
\hline Week 8 & $504.24 \pm 45.68$ & $481.51 \pm 24.24$ & $484.15 \pm 36.64$ & $472.64 \pm 38.26$ & $462.24 \pm 57.39$ & $278.05 \pm 17.19$ & $292.46 \pm 22.75$ & $281.37 \pm 16.37$ & $294.11 \pm 19.63$ & $297.73 \pm 29.69$ \\
\hline Week 9 & $524.03 \pm 50.13$ & $499.86 \pm 27.51$ & $500.70 \pm 39.07$ & $491.34 \pm 42.61$ & $486.42 \pm 61.49$ & $284.89 \pm 17.63$ & $298.72 \pm 21.30$ & $290.25 \pm 16.83$ & $302.56 \pm 20.31$ & $306.37 \pm 35.62$ \\
\hline Week 10 & $540.27 \pm 51.91$ & $515.21 \pm 29.75$ & $518.21 \pm 42.50$ & $506.00 \pm 44.62$ & $504.10 \pm 63.04$ & $290.98 \pm 18.51$ & $305.35 \pm 22.89$ & $294.29 \pm 17.63$ & $306.82 \pm 21.08$ & $311.35 \pm 30.26$ \\
\hline Week 11 & $554.74 \pm 53.37$ & $530.09 \pm 31.38$ & $535.84 \pm 43.73$ & $517.51 \pm 46.68$ & $522.36 \pm 63.95$ & $293.32 \pm 20.43$ & $311.34 \pm 24.87$ & $299.03 \pm 17.21$ & $312.11 \pm 20.34$ & $317.81 \pm 31.89$ \\
\hline Week 12 & $568.86 \pm 56.02$ & $541.83 \pm 32.71$ & $551.40 \pm 43.12$ & $531.23 \pm 49.72$ & $535.79 \pm 64.00$ & $295.05 \pm 20.43$ & $313.06 \pm 26.75$ & $301.39 \pm 17.95$ & $314.82 \pm 24.76$ & $318.11 \pm 32.82$ \\
\hline Week 13 & $571.25 \pm 57.02$ & $545.17 \pm 36.21$ & $551.05 \pm 45.97$ & $532.95 \pm 50.02$ & $539.01 \pm 64.88$ & $298.81 \pm 21.82$ & $318.78 \pm 27.34$ & $305.73 \pm 19.31$ & $318.57 \pm 28.18$ & $317.96 \pm 33.46$ \\
\hline
\end{tabular}

Values represent mean \pm SD. SRE: water extract of Saposhnikoviae Radix.

Table 2. Food consumption values (g/day) in male and female rats during oral administration of SRE for 13 weeks

\begin{tabular}{|c|c|c|c|c|c|c|c|c|c|c|}
\hline \multirow{2}{*}{$\begin{array}{c}\text { Sex } \\
\text { SRE dose } \\
(\mathrm{mg} / \mathrm{kg} / \text { day })\end{array}$} & \multicolumn{5}{|c|}{ Male (each group, $n=10$ ) } & \multicolumn{5}{|c|}{ Female (each group, $\mathrm{n}=10$ ) } \\
\hline & 0 (control) & 500 & 1000 & 2000 & 5000 & 0 (control) & 500 & 1000 & 2000 & 5000 \\
\hline \multicolumn{11}{|c|}{ Food consumption (g/day) } \\
\hline Week 0 & $23.22 \pm 1.59$ & $22.18 \pm 0.76$ & $23.61 \pm 1.59$ & $22.92 \pm 3.03$ & $22.56 \pm 1.94$ & $18.05 \pm 1.85$ & $18.12 \pm 2.76$ & $19.27 \pm 1.83$ & $17.84 \pm 1.38$ & $18.70 \pm 3.06$ \\
\hline Week 1 & $28.16 \pm 1.88$ & $27.90 \pm 1.88$ & $27.76 \pm 1.18$ & $27.18 \pm 2.05$ & $26.00 \pm 2.33$ & $21.55 \pm 2.78$ & $21.06 \pm 1.26$ & $19.69 \pm 1.91$ & $20.56 \pm 1.63$ & $20.54 \pm 4.56$ \\
\hline Week 2 & $29.47 \pm 1.73$ & $27.77 \pm 2.01$ & $28.23 \pm 1.40$ & $27.84 \pm 1.74$ & $24.92 \pm 1.54^{* * *}$ & $21.20 \pm 1.55$ & $20.83 \pm 2.48$ & $20.34 \pm 1.01$ & $19.89 \pm 3.30$ & $20.44 \pm 1.92$ \\
\hline Week 3 & $29.98 \pm 4.35$ & $30.17 \pm 1.13$ & $28.64 \pm 1.47$ & $27.86 \pm 2.23$ & $25.91 \pm 2.24$ & $20.02 \pm 2.11$ & $23.12 \pm 0.93$ & $20.36 \pm 2.72$ & $22.96 \pm 1.74$ & $20.46 \pm 3.61$ \\
\hline Week 4 & $31.08 \pm 2.87$ & $29.22 \pm 1.93$ & $28.16 \pm 1.24$ & $27.65 \pm 2.42$ & $26.49 \pm 3.29$ & $20.75 \pm 4.24$ & $21.21 \pm 2.96$ & $21.09 \pm 1.23$ & $20.38 \pm 2.01$ & $22.97 \pm 3.96$ \\
\hline Week 5 & $30.93 \pm 4.69$ & $29.10 \pm 2.05$ & $30.38 \pm 0.70$ & $27.83 \pm 2.19$ & $24.35 \pm 2.25^{* *}$ & $21.88 \pm 1.06$ & $22.12 \pm 2.27$ & $21.05 \pm 1.90$ & $22.51 \pm 3.65$ & $22.32 \pm 3.82$ \\
\hline Week 6 & $32.55 \pm 2.49$ & $30.07 \pm 2.82$ & $30.82 \pm 2.04$ & $28.75 \pm 3.71$ & $28.83 \pm 1.35$ & $23.66 \pm 1.38$ & $23.75 \pm 2.28$ & $22.31 \pm 1.46$ & $22.45 \pm 3.85$ & $22.95 \pm 1.45$ \\
\hline Week 7 & $28.96 \pm 3.26$ & $27.41 \pm 1.82$ & $27.90 \pm 2.69$ & $26.17 \pm 2.69$ & $24.53 \pm 2.14$ & $19.38 \pm 2.17$ & $21.85 \pm 2.14$ & $18.27 \pm 1.75$ & $20.38 \pm 1.03$ & $19.32 \pm 2.18$ \\
\hline Week 8 & $31.42 \pm 3.92$ & $29.49 \pm 1.59$ & $28.06 \pm 2.06$ & $29.24 \pm 2.32$ & $26.81 \pm 1.04$ & $20.79 \pm 1.65$ & $20.16 \pm 3.06$ & $19.30 \pm 0.61$ & $20.63 \pm 1.17$ & $20.90 \pm 1.06$ \\
\hline Week 9 & $31.84 \pm 4.09$ & $30.93 \pm 1.09$ & $29.84 \pm 1.55$ & $29.11 \pm 2.61$ & $27.75 \pm 1.56$ & $20.43 \pm 0.75$ & $20.15 \pm 2.60$ & $21.76 \pm 2.94$ & $21.24 \pm 1.25$ & $20.73 \pm 3.34$ \\
\hline Week 10 & $33.27 \pm 3.93$ & $31.58 \pm 2.12$ & $30.71 \pm 1.69$ & $28.72 \pm 3.47^{*}$ & $27.24 \pm 3.18^{*}$ & $21.42 \pm 2.34$ & $21.36 \pm 1.83$ & $19.72 \pm 1.61$ & $20.06 \pm 2.72$ & $20.53 \pm 2.49$ \\
\hline Week 11 & $32.72 \pm 3.86$ & $30.65 \pm 1.71$ & $31.99 \pm 2.00$ & $27.22 \pm 2.85^{* * *}$ & $28.06 \pm 3.07^{* * *}$ & $20.08 \pm 2.46$ & $22.24 \pm 2.92$ & $19.91 \pm 2.87$ & $20.79 \pm 1.75$ & $19.72 \pm 1.61$ \\
\hline Week 12 & $32.16 \pm 3.64$ & $30.19 \pm 0.70$ & $29.30 \pm 1.78$ & $27.56 \pm 3.09^{*}$ & $25.45 \pm 3.79^{*}$ & $19.67 \pm 1.86$ & $18.50 \pm 5.41$ & $17.42 \pm 3.41$ & $19.06 \pm 2.62$ & $18.75 \pm 1.29$ \\
\hline Week 13 & $31.68 \pm 0.60$ & $29.18 \pm 2.53$ & $29.12 \pm 1.59$ & $26.70 \pm 1.56^{* * *}$ & $26.67 \pm 3.22$ & $20.47 \pm 2.43$ & $21.39 \pm 3.21$ & $20.48 \pm 2.47$ & $19.81 \pm 3.01$ & $18.03 \pm 2.54$ \\
\hline
\end{tabular}

Values represent mean \pm SD. Significantly different values from the control using Dunnett's test (two-tailed): ${ }^{*} p<0.05,{ }^{* *} p<0.01$ versus sex-matched control. SRE: water extract of Saposhnikoviae Radix. 
Table 3. Values of qualitative urinalysis in male and female rats after oral administration of SRE for 13 weeks

\begin{tabular}{|c|c|c|c|c|c|c|c|c|c|c|c|}
\hline \multirow{2}{*}{$\begin{array}{l}\text { Sex } \\
\text { SRE dose (mg/kg/day) }\end{array}$} & & \multicolumn{5}{|c|}{ Male (each group, $n=5$ ) } & \multicolumn{5}{|c|}{ Female (each group, $\mathrm{n}=5$ ) } \\
\hline & & 0 (control) & 500 & 1000 & 2000 & 5000 & 0 (control) & 500 & 1000 & 2000 & 5000 \\
\hline Glucose & Negative & $5 / 5$ & $5 / 5$ & $5 / 5$ & $5 / 5$ & $5 / 5$ & $5 / 5$ & $5 / 5$ & $5 / 5$ & $5 / 5$ & $5 / 5$ \\
\hline Bilirubin & Negative & $5 / 5$ & $5 / 5$ & $5 / 5$ & $5 / 5$ & $5 / 5$ & $5 / 5$ & $5 / 5$ & $5 / 5$ & $5 / 5$ & $5 / 5$ \\
\hline \multirow[t]{3}{*}{ Ketone bodies } & Negative & $2 / 5$ & $3 / 5$ & $3 / 5$ & $3 / 5$ & $3 / 5$ & $4 / 5$ & $4 / 5$ & $5 / 5$ & $5 / 5$ & $5 / 5$ \\
\hline & Trace & $2 / 5$ & $1 / 5$ & $1 / 5$ & $2 / 5$ & $2 / 5$ & $1 / 5$ & $1 / 5$ & $0 / 5$ & $0 / 5$ & $0 / 5$ \\
\hline & 1 Positive & $1 / 5$ & $1 / 5$ & $1 / 5$ & $0 / 5$ & $0 / 5$ & $1 / 5$ & $2 / 5$ & $3 / 5$ & $1 / 5$ & $1 / 5$ \\
\hline \multirow[t]{3}{*}{ Occult blood } & Negative & $4 / 5$ & $4 / 5$ & $2 / 5$ & $4 / 5$ & $5 / 5$ & $0 / 5$ & $1 / 5$ & $0 / 5$ & $0 / 5$ & $0 / 5$ \\
\hline & Trace & $1 / 5$ & $1 / 5$ & $3 / 5$ & $0 / 5$ & $0 / 5$ & $0 / 5$ & $1 / 5$ & $1 / 5$ & $0 / 5$ & $1 / 5$ \\
\hline & 1 Positive & $0 / 5$ & $0 / 5$ & $0 / 5$ & $1 / 5$ & $0 / 5$ & & & & & \\
\hline \multirow[t]{3}{*}{ Protein } & Negative & $3 / 5$ & $2 / 5$ & $0 / 5$ & $4 / 5$ & $3 / 5$ & $5 / 5$ & $5 / 5$ & $5 / 5$ & $5 / 5$ & $5 / 5$ \\
\hline & Trace & $1 / 5$ & $2 / 5$ & $3 / 5$ & $0 / 5$ & $1 / 5$ & & & & & \\
\hline & 1 Positive & $1 / 5$ & $1 / 5$ & $2 / 5$ & $1 / 5$ & $1 / 5$ & & & & & \\
\hline \multirow[t]{2}{*}{ Urobilinogen } & 0.2 & $4 / 5$ & $5 / 5$ & $5 / 5$ & $5 / 5$ & $5 / 5$ & $5 / 5$ & $5 / 5$ & $5 / 5$ & $5 / 5$ & $5 / 5$ \\
\hline & 1.0 & $1 / 5$ & $0 / 5$ & $0 / 5$ & $0 / 5$ & $0 / 5$ & & & & & \\
\hline Nitrite & Negative & $5 / 5$ & $5 / 5$ & $5 / 5$ & $5 / 5$ & $5 / 5$ & $5 / 5$ & $5 / 5$ & $5 / 5$ & $5 / 5$ & $5 / 5$ \\
\hline \multirow[t]{3}{*}{ Leukocyte } & Negative & $4 / 5$ & $5 / 5$ & $4 / 5$ & $4 / 5$ & $4 / 5$ & $5 / 5$ & $5 / 5$ & $5 / 5$ & $5 / 5$ & $5 / 5$ \\
\hline & Trace & $0 / 5$ & $0 / 5$ & $1 / 5$ & $1 / 5$ & $0 / 5$ & & & & & \\
\hline & 1 Positive & $1 / 5$ & $0 / 5$ & $0 / 5$ & $0 / 5$ & $1 / 5$ & & & & & \\
\hline Color & Colorless & $5 / 5$ & $5 / 5$ & $5 / 5$ & $5 / 5$ & $5 / 5$ & $5 / 5$ & $5 / 5$ & $5 / 5$ & $5 / 5$ & $5 / 5$ \\
\hline
\end{tabular}

Values are expressed as number of animals with the sign/number of animals examined and represent mean \pm SD. SRE: water extract of Saposhnikoviae Radix.

ber of parameters (e.g., total cholesterol, triglycerides, and protein), particularly in males dosed with 500 and 1,000 $\mathrm{mg} / \mathrm{kg}$ SRE. It is thought that these events were not related to SRE exposure because they were low in incidence, did not occur in a dose-response fashion, the direction of change was not associated with adversity, and the changes reflected adaptive responses following effects on the liver.

- Hematology: The results of the hematological analysis are presented in Table 5. There were no significant differences between vehicle and SRE-treated groups except in the $2,000 \mathrm{mg} / \mathrm{kg}$ SRE-treated male group (increase of hematocrit) and the $500 \mathrm{mg} / \mathrm{kg}$ SRE-treated female group (increase of RDW and reticulocyte\%). It is assumed that changes in those parameters would be random biological variations because of their minimal changes and lack of dose-response relationship.

- Organ weights: Following 13 weeks of SRE administration, there were no significant changes in organ weights except in the lung and thymus of females (Table 6). Mean lung weights increased by $10.5 \%$ and $8.5 \%$ in female rats dosed with 500 and $1,000 \mathrm{mg} / \mathrm{kg}$ SRE, respectively. The average thymus weight increased by $24.6 \%$ in female rats dosed with 1,000 mg SRE/kg/day.

- Histopathology: The microscopic findings of male and female rats $(\mathrm{n}=10$ for each sex $)$ dosed with 0 and $5,000 \mathrm{mg} \mathrm{SRE} / \mathrm{kg} /$ day are summarized in Table 7. No significant changes were observed in any tissue analyzed except kidney, lung, pituitary, and vagina. In the kidney, crystallization in the outer stripe of the medulla was observed in one male rat. An ectopic thymus and ultimo- branchial body cyst were found in a control male rat and a $5,000 \mathrm{mg} \mathrm{SRE} / \mathrm{kg} /$ day-treated male rat, respectively. In the lung, inflammatory cell infiltration was observed in several control rats (2/10 males, $1 / 10$ females) and SREadministrated rats (3/10 males, 1/10 females). A bronchioloalveolar lesion was observed in the lungs of several control (2/10 males, $0 / 10$ females) and SRE-administered rats (1/10 males, 1/10 females). A cyst in the pars nervosa of the pituitary and an epidermal cyst in the vagina were observed in one control female rat (Table 7). However, these findings are not expected to be linked to SRE toxicity because the histopathological signs were normal to mild, and there was no dose-dependent occurrence of SRE administration.

- Antihyperuricemic effect of SRE: The antihyperuricemic potential of SRE was evaluated in PO-induced gout in male ICR mice. PO $(250 \mathrm{mg} / \mathrm{kg})$, a uricase inhibitor, was intraperitoneally (i.p.) injected with $0.9 \% \mathrm{NaCl}$ in PBS in the presence of SRE at 125, 250, or $500 \mathrm{mg} / \mathrm{kg}$, allopurinol (an XO inhibitor in the liver, $5 \mathrm{mg} / \mathrm{kg}$ ), and benzbromarone (a UA transporter 1 inhibitor in renal tubular cells, $10 \mathrm{mg} / \mathrm{kg}$ ) (27) for 8 days.

- Changes in body and organ weight: All animals survived until the scheduled sacrifice day. The body weight of each mouse was measured at baseline (day 0) and on the final day (day 8). The change in body weight was not significantly different among any of the seven groups (Table 8). There were no significant changes in thymus, spleen, or kidney weights among the groups. However, PO insult caused severe liver atrophy and resulted in an 
Table 4. Clinical chemistry values in male and female rats after oral administration of SRE for 13 weeks

\begin{tabular}{|c|c|c|c|c|c|c|c|c|c|c|}
\hline \multirow{2}{*}{$\begin{array}{c}\text { Sex } \\
\text { SRE dose } \\
(\mathrm{mg} / \mathrm{kg} / \text { day })\end{array}$} & \multicolumn{5}{|c|}{ Male (each group, $n=10$ ) } & \multicolumn{5}{|c|}{ Female (each group, $\mathrm{n}=10$ ) } \\
\hline & 0 (control) & 500 & 1000 & 2000 & 5000 & 0 (control) & 500 & 1000 & 2000 & 5000 \\
\hline AST (IU/L) & $158 \pm 28$ & $178 \pm 27$ & $174 \pm 59$ & $169 \pm 34$ & $159 \pm 27$ & $196 \pm 136$ & $193 \pm 44$ & $173 \pm 63$ & $188 \pm 39$ & $167 \pm 28$ \\
\hline $\operatorname{ALT}(\mathrm{IU} / \mathrm{L})$ & $33 \pm 5$ & $33 \pm 7$ & $35 \pm 13$ & $34 \pm 4$ & $33 \pm 4$ & $40 \pm 30$ & $38 \pm 14$ & $29 \pm 10$ & $37 \pm 15$ & $30 \pm 7$ \\
\hline ALP (IU/L) & $239 \pm 37$ & $282 \pm 74$ & $231 \pm 73$ & $268 \pm 22$ & $247 \pm 43$ & $121 \pm 34$ & $122 \pm 23$ & $104 \pm 18$ & $113 \pm 27$ & $94 \pm 16$ \\
\hline Total bilirubin (mg/dL) & $0.07 \pm 0.05$ & $0.0 \pm 0.0$ & $0.0 \pm 0.0$ & $0.05 \pm 0.02$ & $0.06 \pm 0.03$ & $0.09 \pm 0.03$ & $0.07 \pm 0.03$ & $0.09 \pm 0.03$ & $0.09 \pm 0.06$ & $0.09 \pm 0.02$ \\
\hline BUN (mg/dL) & $14.0 \pm 1.5$ & $0.05 \pm 0.03$ & $0.06 \pm 0.03$ & $14.7 \pm 2.1$ & $14.2 \pm 1.6$ & $16.4 \pm 2.4$ & $16.0 \pm 1.2$ & $17.2 \pm 2.1$ & $16.8 \pm 1.3$ & $17.1 \pm 2.5$ \\
\hline Creatine (mg/dL) & $0.46 \pm 0.02$ & $45.0 \pm 1.9$ & $14.6 \pm 2.4$ & $0.47 \pm 0.02$ & $0.46 \pm 0.04$ & $0.57 \pm 0.03$ & $0.57 \pm 0.05$ & $0.59 \pm 0.05$ & $0.58 \pm 0.06$ & $0.56 \pm 0.05$ \\
\hline Uric $\operatorname{acid}(\mathrm{mg} / \mathrm{dL})$ & $1.2 \pm 0.3$ & $0.49 \pm 0.03$ & $0.46 \pm 0.03$ & $1.3 \pm 0.5$ & $1.6 \pm 0.6$ & $1.5 \pm 0.05$ & $1.8 \pm 0.6$ & $1.5 \pm 0.4$ & $1.6 \pm 0.5$ & $1.5 \pm 0.5$ \\
\hline Glucose (mg/dL) & $136 \pm 21$ & $1.4 \pm 0.05$ & $1.3 \pm 0.5$ & $138 \pm 28$ & $129 \pm 26$ & $123 \pm 21$ & $119 \pm 27$ & $113 \pm 18$ & $121 \pm 35$ & $123 \pm 27$ \\
\hline Cholesterol, total $(\mathrm{mg} / \mathrm{dL})$ & $72 \pm 16$ & $128 \pm 22$ & $134 \pm 22$ & $75 \pm 15$ & $69 \pm 13$ & $94 \pm 17$ & $88 \pm 16$ & $84 \pm 26$ & $90 \pm 22$ & $88 \pm 21$ \\
\hline Triglycerides (mg/dL) & $34 \pm 14$ & $65 \pm 14$ & $75 \pm 18$ & $42 \pm 19$ & $47 \pm 17$ & $27 \pm 6$ & $26 \pm 12$ & $27 \pm 14$ & $30 \pm 10$ & $31 \pm 14$ \\
\hline Protein, total $(\mathrm{g} / \mathrm{dL})$ & $6.0 \pm 0.3$ & $42 \pm 22$ & $52 \pm 20$ & $6.2 \pm 0.3$ & $6.1 \pm 0.2$ & $6.9 \pm 0.5$ & $6.7 \pm 0.4$ & $6.8 \pm 0.6$ & $6.9 \pm 0.2$ & $7.0 \pm 0.3$ \\
\hline Albumin $(\mathrm{g} / \mathrm{dL})$ & $2.3 \pm 0.1$ & $6.2 \pm 0.3$ & $6.1 \pm 0.2$ & $2.4 \pm 0.1$ & $2.3 \pm 0.1$ & $3.1 \pm 0.3$ & $2.9 \pm 0.3$ & $3.0 \pm 0.4$ & $3.0 \pm 0.2$ & $3.2 \pm 0.2$ \\
\hline $\mathrm{A} / \mathrm{G}$ ratio & $0.63 \pm 0.05$ & $2.3 \pm 0.1$ & $2.4 \pm 0.1$ & $0.63 \pm 0.04$ & $0.61 \pm 0.04$ & $0.80 \pm 0.06$ & $0.75 \pm 0.08$ & $0.79 \pm 0.07$ & $0.76 \pm 0.05$ & $0.82 \pm 0.05$ \\
\hline LDH (IU/L) & $2234 \pm 639$ & $0.61 \pm 0.06$ & $0.65 \pm 0.07$ & $2473 \pm 812$ & $2296 \pm 708$ & $2149 \pm 1053$ & $2457 \pm 720$ & $2175 \pm 899$ & $2515 \pm 726$ & $2381 \pm 540$ \\
\hline CPK (U/L) & $1115 \pm 379$ & $2650 \pm 614$ & $2355 \pm 880$ & $1164 \pm 433$ & $1136 \pm 356$ & $1032 \pm 486$ & $1176 \pm 354$ & $1070 \pm 374$ & $1225 \pm 376$ & $1118 \pm 291$ \\
\hline $\mathrm{Ca}(\mathrm{mg} / \mathrm{dL})$ & $9.0 \pm 0.3$ & $1366 \pm 258$ & $1053 \pm 388$ & $9.3 \pm 0.3$ & $9.2 \pm 0.2$ & $9.7 \pm 0.3$ & $9.4 \pm 0.4$ & $9.6 \pm 0.5$ & $9.7 \pm 0.4$ & $9.7 \pm 0.3$ \\
\hline $\mathrm{P}_{\mathrm{i}}(\mathrm{mg} / \mathrm{dL})$ & $6.5 \pm 0.5$ & $9.1 \pm 0.3$ & $9.3 \pm 0.4$ & $6.6 \pm 0.6$ & $6.5 \pm 0.6$ & $5.4 \pm 0.7$ & $5.3 \pm 0.8$ & $5.7 \pm 1.0$ & $5.7 \pm 0.6$ & $5.4 \pm 0.7$ \\
\hline $\mathrm{Mg}(\mathrm{mg} / \mathrm{dL})$ & $2.3 \pm 0.2$ & $6.6 \pm 0.7$ & $6.7 \pm 0.7$ & $2.4 \pm 0.2$ & $2.3 \pm 0.2$ & $2.4 \pm 0.2$ & $2.5 \pm 0.2$ & $2.5 \pm 0.2$ & $2.5 \pm 0.1$ & $2.5 \pm 0.2$ \\
\hline $\mathrm{Na}(\mathrm{mmol} / \mathrm{L})$ & $145 \pm 3$ & $2.3 \pm 0.2$ & $2.4 \pm 0.1$ & $142 \pm 2$ & $142 \pm 4$ & $143 \pm 1$ & $143 \pm 1$ & $143 \pm 2$ & $142 \pm 2$ & $142 \pm 1$ \\
\hline $\mathrm{K}(\mathrm{mmol} / \mathrm{L})$ & $4.7 \pm 0.3$ & $145 \pm 3$ & $144 \pm 3$ & $4.7 \pm 0.2$ & $4.7 \pm 0.3$ & $4.3 \pm 0.4$ & $4.4 \pm 0.3$ & $4.3 \pm 0.1$ & $4.5 \pm 0.3$ & $4.5 \pm 0.2$ \\
\hline $\mathrm{Cl}(\mathrm{mmol} / \mathrm{L})$ & $101 \pm 3$ & $4.8 \pm 0.2$ & $4.8 \pm 0.3$ & $102 \pm 1$ & $103 \pm 2$ & $102 \pm 2$ & $103 \pm 2$ & $103 \pm 3$ & $102 \pm 2$ & $102 \pm 2$ \\
\hline
\end{tabular}

Values represent mean \pm SD. A/G ratio, albumin/globulin ratio; ALP, alkaline phosphatase; ALT, alanine aminotransferase; AST, aspartate aminotransferase; BUN, blood urea nitrogen;

$\mathrm{Ca}$, calcuin; $\mathrm{Cl}$, chloride; CPK, creatine phosphokinase; $\mathrm{K}$, potassium; LDH, lactate dehydrogenase; Mg, magnesium; Na, sodium; Pi, iorganic phophorus; SRE, water extract of Saposhnikoviae Radix. 
Table 5. Hematological values in male and female rats orally dosed with SRE for 13 weeks

\begin{tabular}{|c|c|c|c|c|c|c|c|c|c|c|}
\hline Sex & & & Male & & & & & Female & & \\
\hline Dose $(\mathrm{mg} / \mathrm{kg} /$ day $)$ & 0 (control) & 500 & 1000 & 2000 & 5000 & 0 (control) & 500 & 1000 & 2000 & 5000 \\
\hline Number of animals & 10 & 10 & 10 & 10 & 10 & 10 & 10 & 10 & 10 & 10 \\
\hline $\mathrm{WBC}\left(10^{3} / \mu \mathrm{L}\right)$ & $6.76 \pm 2.41$ & $7.28 \pm 0.93$ & $6.67 \pm 1.78$ & $7.71 \pm 2.32$ & $7.28 \pm 2.17$ & $3.99 \pm 0.31$ & $4.10 \pm 1.00$ & $3.93 \pm 0.82$ & $3.92 \pm 1.14$ & $4.09 \pm 0.81$ \\
\hline Neutrophils $\left(10^{3} / \mu \mathrm{L}\right)$ & $0.92 \pm 0.35$ & $1.26 \pm 0.39$ & $1.03 \pm 0.37$ & $1.19 \pm 0.33$ & $1.37 \pm 0.39$ & $0.60 \pm 0.17$ & $0.77 \pm 0.30$ & $0.57 \pm 0.22$ & $0.59 \pm 0.20$ & $0.57 \pm 0.20$ \\
\hline Eosinophils $\left(10^{3} / \mu \mathrm{L}\right)$ & $0.08 \pm 0.03$ & $0.08 \pm 0.03$ & $0.08 \pm 0.02$ & $0.08 \pm 0.02$ & $0.07 \pm 0.03$ & $0.06 \pm 0.02$ & $0.05 \pm 0.02$ & $0.06 \pm 0.01$ & $0.05 \pm 0.01$ & $0.04 \pm 0.02$ \\
\hline Basophils $\left(10^{3} / \mu \mathrm{L}\right)$ & $0.00 \pm 0.00$ & $0.00 \pm 0.00$ & $0.00 \pm 0.00$ & $0.00 \pm 0.00$ & $0.00 \pm 0.00$ & $0.00 \pm 0.00$ & $0.00 \pm 0.00$ & $0.00 \pm 0.00$ & $0.00 \pm 0.00$ & $0.00 \pm 0.00$ \\
\hline Lymphocytes $\left(10^{3} / \mu \mathrm{L}\right)$ & $5.57 \pm 2.13$ & $5.68 \pm 0.85$ & $5.37 \pm 1.61$ & $6.18 \pm 1.98$ & $5.58 \pm 1.76$ & $3.20 \pm 0.31$ & $3.13 \pm 0.76$ & $3.18 \pm 0.64$ & $3.16 \pm 0.97$ & $3.32 \pm 0.81$ \\
\hline Monocytes $\left(10^{3} / \mu \mathrm{L}\right)$ & $0.13 \pm 0.05$ & $0.20 \pm 0.07$ & $0.14 \pm 0.50$ & $0.20 \pm 0.12$ & $0.19 \pm 0.08$ & $0.10 \pm 0.04$ & $0.11 \pm 0.04$ & $0.10 \pm 0.04$ & $0.09 \pm 0.04$ & $0.12 \pm 0.07$ \\
\hline Leucocytes $\left(10^{3} / \mu \mathrm{L}\right)$ & $0.05 \pm 0.05$ & $0.06 \pm 0.04$ & $0.04 \pm 0.03$ & $0.05 \pm 0.04$ & $0.07 \pm 0.07$ & $0.02 \pm 0.01$ & $0.03 \pm 0.01$ & $0.02 \pm 0.01$ & $0.03 \pm 0.01$ & $0.03 \pm 0.02$ \\
\hline Neutrophils \% & $14.4 \pm 4.7$ & $17.4 \pm 4.9$ & $15.8 \pm 4.7$ & $16.0 \pm 4.5$ & $19.1 \pm 3.6$ & $15.0 \pm 4.1$ & $18.4 \pm 4.4$ & $14.2 \pm 3.2$ & $15.49 \pm 4.44$ & $14.44 \pm 6.06$ \\
\hline Eosinophils \% & $1.2 \pm 0.4$ & $1.1 \pm 0.5$ & $1.2 \pm 0.3$ & $1.0 \pm 0.3$ & $1.0 \pm 0.2$ & $1.6 \pm 0.6$ & $1.4 \pm 0.5$ & $1.6 \pm 0.4$ & $1.4 \pm 0.5$ & $1.1 \pm 0.4$ \\
\hline Basophils \% & $0.1 \pm 0.1$ & $0.0 \pm 0.0$ & $0.0 \pm 0.0$ & $0.0 \pm 0.0$ & $0.0 \pm 0.0$ & $0.1 \pm 0.0$ & $0.1 \pm 0.1$ & $0.0 \pm 0.0$ & $0.0 \pm 0.0$ & $0.1 \pm 0.1$ \\
\hline Lymphocytes \% & $81.8 \pm 5.0$ & $78.0 \pm 5.7$ & $80.2 \pm 5.0$ & $79.8 \pm 4.1$ & $76.6 \pm 4.1$ & $80.3 \pm 5.2$ & $76.8 \pm 4.2$ & $81.2 \pm 3.8$ & $80.1 \pm 5.0$ & $80.7 \pm 6.9$ \\
\hline Monocytes \% & $2.0 \pm 0.4$ & $2.8 \pm 0.9$ & $2.2 \pm 1.0$ & $2.5 \pm 1.1$ & $2.5 \pm 0.8$ & $2.5 \pm 1.1$ & $2.8 \pm 0.9$ & $2.4 \pm 0.9$ & $2.3 \pm 0.5$ & $3.0 \pm 1.4$ \\
\hline Large unstained cells \% & $0.7 \pm 0.4$ & $0.8 \pm 0.5$ & $0.5 \pm 0.2$ & $0.6 \pm 0.4$ & $0.8 \pm 0.6$ & $0.6 \pm 0.3$ & $0.6 \pm 0.2$ & $0.6 \pm 0.3$ & $0.6 \pm 0.2$ & $0.8 \pm 0.3$ \\
\hline $\operatorname{RBCs}\left(10^{6} / \mu \mathrm{L}\right)$ & $8.31 \pm 0.37$ & $8.39 \pm 0.34$ & $8.42 \pm 0.32$ & $8.74 \pm 0.34$ & $8.60 \pm 0.42$ & $7.85 \pm 0.30$ & $7.89 \pm 0.29$ & $7.79 \pm 0.32$ & $7.78 \pm 0.31$ & $7.71 \pm 0.32$ \\
\hline Hemoglobin (g/dL) & $14.1 \pm 0.7$ & $14.3 \pm 0.5$ & $14.4 \pm 0.4$ & $14.9 \pm 0.7$ & $14.6 \pm 0.6$ & $14.1 \pm 0.5$ & $14.1 \pm 0.4$ & $13.9 \pm 0.5$ & $13.9 \pm 0.5$ & $14.0 \pm 0.4$ \\
\hline RDW (\%) & $12.9 \pm 0.9$ & $12.6 \pm 0.5$ & $12.8 \pm 0.9$ & $12.4 \pm 0.8$ & $12.3 \pm 0.7$ & $11.0 \pm 0.3$ & $11.5 \pm 0.6^{*}$ & $11.2 \pm 0.4$ & $11.3 \pm 0.7$ & $10.9 \pm 0.3$ \\
\hline HCT (\%) & $43.5 \pm 1.6$ & $44.2 \pm 1.8$ & $44.0 \pm 1.2$ & $45.8 \pm 1.6^{*}$ & $44.9 \pm 1.6$ & $42.1 \pm 1.4$ & $42.5 \pm 1.4$ & $41.8 \pm 1.7$ & $41.6 \pm 1.5$ & $41.5 \pm 1.5$ \\
\hline $\operatorname{MCV}\left(10^{-15} \mathrm{~L}\right)$ & $52.3 \pm 1.3$ & $52.7 \pm 0.7$ & $52.3 \pm 0.7$ & $52.4 \pm 1.3$ & $52.2 \pm 1.6$ & $53.6 \pm 1.3$ & $53.8 \pm 1.2$ & $53.7 \pm 1.2$ & $53.5 \pm 1.0$ & $53.9 \pm 1.0$ \\
\hline $\mathrm{MCH}(\mathrm{pg})$ & $17.0 \pm 0.6$ & $17.1 \pm 0.4$ & $17.1 \pm 0.4$ & $17.1 \pm 0.7$ & $17.0 \pm 0.7$ & $18.0 \pm 0.4$ & $17.9 \pm 0.4$ & $17.8 \pm 0.3$ & $18.1 \pm 0.5$ & $18.1 \pm 0.5$ \\
\hline $\mathrm{MCHC}(\mathrm{g} / \mathrm{dL})$ & $32.5 \pm 0.5$ & $32.5 \pm 0.6$ & $32.7 \pm 0.6$ & $32.5 \pm 0.8$ & $32.5 \pm 0.4$ & $33.6 \pm 0.6$ & $33.3 \pm 0.4$ & $33.2 \pm 0.6$ & $33.6 \pm 0.5$ & $33.6 \pm 0.5$ \\
\hline Reticulocyte \% & $2.25 \pm 0.41$ & $2.19 \pm 0.43$ & $2.36 \pm 0.93$ & $1.93 \pm 0.47$ & $2.04 \pm 0.45$ & $2.04 \pm 0.17$ & $2.30 \pm 0.34^{* * *}$ & $2.00 \pm 0.32$ & $1.99 \pm 0.25$ & $1.80 \pm 0.30$ \\
\hline Platelets $\left(10^{3} / \mu \mathrm{L}\right)$ & $1063 \pm 70$ & $1099 \pm 103$ & $1034 \pm 45$ & $1056 \pm 147$ & $1043 \pm 121$ & $1140 \pm 99$ & $1131 \pm 112$ & $1072 \pm 72$ & $1167 \pm 76$ & $1147 \pm 63$ \\
\hline $\operatorname{MPV}\left(10^{-15} \mathrm{~L}\right)$ & $6.5 \pm 0.6$ & $6.4 \pm 0.9$ & $6.5 \pm 0.7$ & $6.4 \pm 0.9$ & $6.4 \pm 0.7$ & $6.8 \pm 1.0$ & $6.9 \pm 0.8$ & $7.1 \pm 0.8$ & $7.1 \pm 0.7$ & $7.1 \pm 0.8$ \\
\hline
\end{tabular}

Values represent means \pm SD. Values significantly different from the control using Dunnett's test (two-tailed): ${ }^{*} p<0.05,{ }^{* *} p<0.01$ versus sex-matched control. BA, basophils; BAP, percent of basophils; EO, eosinophils; EOP, percent of eosinophils; Hb, hemoglobin; HCT, hematocrit; LUC, large unstained cells; LUP, percent of large unstained cells; LY, lymphocytes; LYP, percent of large unstained cells; MCH, mean corpuscular hemoglobin; MCHC, mean corpuscular hemoglobin concentration; MCV, mean corpuscular volume; MO, monocytes; MOP, percent of monocytes; MPV, mean platelet volume; NE, neutrophils; NEP, percent of neutrophils; PLT, platelets; RBC, red blood cells; RDW, red cell distribution; Reti, reticulocyte; SRE, water extract of Saposhnikoviae Radix; WBC, white blood cells. 
Table 6. Organ weight values in male and female rats after oral administration of SRE for 13 weeks

\begin{tabular}{|c|c|c|c|c|c|c|c|c|c|c|}
\hline Sex & & & Male & & & & & Female & & \\
\hline $\begin{array}{c}\text { Dose } \\
\text { (mg SRE/kg/day) }\end{array}$ & 0 (control) & 500 & 1000 & 2000 & 5000 & 0 (control) & 500 & 1000 & 2000 & 5000 \\
\hline Number of animals & 10 & 10 & 10 & 10 & 10 & 10 & 10 & 10 & 10 & 10 \\
\hline Body weight (g) & $571.25 \pm 57.02$ & $545.17 \pm 36.21$ & $551.05 \pm 45.97$ & $532.95 \pm 50.02$ & $539.01 \pm 64.88$ & $298.81 \pm 21.82$ & $318.78 \pm 27.34$ & $305.73 \pm 19.31$ & $318.57 \pm 28.18$ & $317.96 \pm 33.46$ \\
\hline Testis-Left (g) & $1.77 \pm 0.11$ & $1.79 \pm 0.11$ & $1.78 \pm 0.16$ & $1.71 \pm 0.08$ & $1.75 \pm 0.07$ & NA & NA & NA & NA & NA \\
\hline Testis-Right (g) & $1.77 \pm 0.07$ & $1.79 \pm 0.11$ & $1.80 \pm 0.18$ & $1.70 \pm 0.10$ & $1.74 \pm 00.08$ & NA & NA & NA & NA & NA \\
\hline Ovary-Left (mg) & NA & NA & NA & NA & NA & $38.4 \pm 13.9$ & $41.6 \pm 7.9$ & $37.4 \pm 8.2$ & $45.9 \pm 13.8$ & $43.2 \pm 6.8$ \\
\hline Ovary-Right (mg) & NA & NA & NA & NA & NA & $39.0 \pm 12.9$ & $42.3 \pm 11.0$ & $38.0 \pm 11.3$ & $44.2 \pm 10.4$ & $43.2 \pm 8.5$ \\
\hline Uterus (g) & NA & NA & NA & NA & NA & $0.68 \pm 0.26$ & $0.75 \pm 0.34$ & $0.61 \pm 0.22$ & $0.63 \pm 0.18$ & $0.57 \pm 0.12$ \\
\hline Prostate (g) & $0.90 \pm 0.27$ & $0.87 \pm 0.17$ & $1.00 \pm 0.20$ & $0.85 \pm 0.15$ & $0.91 \pm 0.22$ & NA & NA & NA & NA & NA \\
\hline Spleen (g) & $0.91 \pm 0.17$ & $0.81 \pm 0.09$ & $0.90 \pm 0.19$ & $0.82 \pm 0.10$ & $0.75 \pm 00.13$ & $0.54 \pm 0.06$ & $0.60 \pm 0.12$ & $0.55 \pm 0.05$ & $0.59 \pm 0.15$ & $0.54 \pm 0.09$ \\
\hline Liver (g) & $13.37 \pm 2.16$ & $12.63 \pm 1.55$ & $12.57 \pm 1.12$ & $12.42 \pm 1.76$ & $12.90 \pm 2.41$ & $6.97 \pm 0.63$ & $7.11 \pm 0.70$ & $7.04 \pm 0.86$ & $7.44 \pm 0.69$ & $7.47 \pm 0.83$ \\
\hline Adrenal gland-Left (mg) & $30.0 \pm 4.4$ & $31.5 \pm 9.0$ & $27.1 \pm 4.3$ & $27.7 \pm 3.9$ & $29.3 \pm 3.5$ & $33.4 \pm 4.9$ & $35.1 \pm 4.8$ & $33.1 \pm 6.3$ & $35.8 \pm 5.0$ & $34.7 \pm 4.2$ \\
\hline Adrenal gland-Right (mg) & $28.1 \pm 4.7$ & $29.4 \pm 7.9$ & $26.2 \pm 3.6$ & $26.3 \pm 3.0$ & $27.4 \pm 3.7$ & $29.5 \pm 4.0$ & $33.3 \pm 3.6$ & $31.2 \pm 7.0$ & $34.0 \pm 4.5$ & $32.5 \pm 5.1$ \\
\hline Kidney-Left (g) & $1.64 \pm 0.17$ & $1.63 \pm 0.17$ & $1.54 \pm 0.13$ & $1.57 \pm 0.16$ & $1.59 \pm 0.16$ & $0.91 \pm 0.08$ & $0.93 \pm 0.08$ & $0.94 \pm 0.09$ & $0.98 \pm 0.09$ & $0.96 \pm 0.14$ \\
\hline Kidney-Right (g) & $1.67 \pm 0.16$ & $1.65 \pm 0.16$ & $1.57 \pm 0.12$ & $1.51 \pm 0.09$ & $1.60 \pm 0.20$ & $0.93 \pm 0.10$ & $0.95 \pm 0.05$ & $0.98 \pm 0.09$ & $0.99 \pm 0.09$ & $0.99 \pm 0.13$ \\
\hline Heart (g) & $1.55 \pm 0.15$ & $1.59 \pm 0.15$ & $1.51 \pm 0.09$ & $1.71 \pm 0.15$ & $1.55 \pm 0.21$ & $0.99 \pm 0.07$ & $1.00 \pm 0.05$ & $1.01 \pm 0.11$ & $1.00 \pm 0.10$ & $1.00 \pm 0.09$ \\
\hline Lung (g) & $1.75 \pm 0.14$ & $1.75 \pm 0.20$ & $1.71 \pm 0.15$ & $2.17 \pm 0.05$ & $1.70 \pm 0.18$ & $1.23 \pm 0.07$ & $1.36 \pm 0.11^{* *}$ & $1.33 \pm 0.06^{* *}$ & $1.27 \pm 0.09$ & $1.26 \pm 0.05$ \\
\hline Brain (g) & $2.11 \pm 0.07$ & $2.13 \pm 0.11$ & $2.17 \pm 0.05$ & $2.13 \pm 0.08$ & $2.12 \pm 0.07$ & $2.00 \pm 0.09$ & $1.97 \pm 0.06$ & $1.95 \pm 0.07$ & $1.99 \pm 0.11$ & $1.94 \pm 0.06$ \\
\hline Pituitary (mg) & $11.4 \pm 2.0$ & $11.2 \pm 1.7$ & $10.9 \pm 1.5$ & $10.5 \pm 1.8$ & $10.6 \pm 1.8$ & $16.7 \pm 6.1$ & $14.2 \pm 2.8$ & $14.4 \pm 3.0$ & $15.7 \pm 3.8$ & $15.7 \pm 4.1$ \\
\hline Thymus (mg) & $277.1 \pm 64.9$ & $237.0 \pm 51.0$ & $226.5 \pm 38.9$ & $245.9 \pm 62.8$ & $235.2 \pm 51.0$ & $234.9 \pm 44.1$ & $278.7 \pm 40.1$ & $292.8 \pm 76.0^{*}$ & $230.5 \pm 54.4$ & $238.8 \pm 37.4$ \\
\hline
\end{tabular}

Values represent mean \pm SD. Significantly different values from the control using Dunnett's test (two-tailed): ${ }^{*} p<0.05,{ }^{* * *} p<0.01$ versus sex-matched control. NA: not applicable; SRE: water extract of Saposhnikoviae Radix. 
Table 7. Summary of histopathology in male and female rats after oral administration of SRE for 13 weeks

\begin{tabular}{|c|c|c|c|c|c|c|c|c|c|}
\hline \multirow{3}{*}{$\begin{array}{l}\text { Dose } \\
\text { (mg SRE/kg/day) }\end{array}$} & \multirow{3}{*}{ Signs } & \multicolumn{4}{|c|}{ Male (each group, $\mathrm{n}=10$ ) } & \multicolumn{4}{|c|}{ Female (each group, $\mathrm{n}=10$ ) } \\
\hline & & \multicolumn{2}{|c|}{0 (control) } & \multicolumn{2}{|c|}{5000} & \multicolumn{2}{|c|}{0 (control) } & \multicolumn{2}{|c|}{5000} \\
\hline & & $\mathrm{N}$ & $\%$ & $\mathrm{~N}$ & $\%$ & $\mathrm{~N}$ & $\%$ & $\mathrm{~N}$ & $\%$ \\
\hline Liver & No remarkable lesions & 10 & 100 & 10 & 100 & 10 & 100 & 10 & 100 \\
\hline \multirow[t]{2}{*}{ Kidney } & No remarkable lesions & 10 & 100 & 9 & 90 & 10 & 100 & 10 & 100 \\
\hline & - Cryst, outer stripe & 0 & 0 & 1 & 10 & 0 & 0 & 0 & 0 \\
\hline Adrenal gland & No remarkable lesions & 10 & 100 & 10 & 100 & 10 & 100 & 10 & 100 \\
\hline Urinary bladder & No remarkable lesions & 10 & 100 & 10 & 100 & 10 & 100 & 10 & 100 \\
\hline Spleen & No remarkable lesions & 10 & 100 & 10 & 100 & 10 & 100 & 10 & 100 \\
\hline \multirow[t]{2}{*}{ Pancreas } & No remarkable lesions & 9 & 90 & 10 & 100 & 10 & 100 & 10 & 100 \\
\hline & Atrophy/fibrosis, acinar, focal & 1 & 10 & 0 & 0 & 10 & 100 & 10 & 100 \\
\hline Thymus & No remarkable lesions & 10 & 100 & 10 & 100 & 10 & 100 & 10 & 100 \\
\hline \multirow[t]{3}{*}{ Thyroid } & No remarkable lesions & 9 & 90 & 9 & 90 & 10 & 100 & 10 & 100 \\
\hline & - Ectopic thymus & 1 & 10 & 0 & 10 & 0 & 0 & 0 & 0 \\
\hline & - Ultimobranchial cyst & 0 & 0 & 1 & 10 & 0 & 0 & 0 & 0 \\
\hline Parathyroid & No remarkable lesions & 9 & 100 & 10 & 100 & 10 & 100 & 10 & 100 \\
\hline Trachea & No remarkable lesions & 10 & 100 & 10 & 100 & 10 & 100 & 10 & 100 \\
\hline Esophagus & No remarkable lesions & 10 & 100 & 10 & 100 & 10 & 100 & 10 & 100 \\
\hline Tongue & No remarkable lesions & 10 & 100 & 10 & 100 & 10 & 100 & 10 & 100 \\
\hline \multirow[t]{3}{*}{ Lung } & No remarkable lesions & 6 & 60 & 6 & 60 & 9 & 90 & 8 & 80 \\
\hline & - Inflammatory cell infiltration & 2 & 20 & 3 & 30 & 1 & 10 & 1 & 10 \\
\hline & - Bronchioloalveolar & 2 & 20 & 1 & 10 & 0 & 0 & 1 & 10 \\
\hline Heart & No remarkable lesions & 10 & 100 & 10 & 100 & 10 & 100 & 10 & 100 \\
\hline Aorta & No remarkable lesions & 10 & 100 & 10 & 100 & 10 & 100 & 10 & 100 \\
\hline Submandibular lymph node & No remarkable lesions & 10 & 100 & 10 & 100 & 10 & 100 & 10 & 100 \\
\hline Mesenteric lymph node & No remarkable lesions & 10 & 100 & 10 & 100 & 10 & 100 & 10 & 100 \\
\hline Salivary gland, submandibular & No remarkable lesions & 10 & 100 & 10 & 100 & 10 & 100 & 10 & 100 \\
\hline Salivary gland, sublingual & No remarkable lesions & 10 & 100 & 10 & 100 & 10 & 100 & 10 & 100 \\
\hline Salivary gland, parotid & No remarkable lesions & 10 & 100 & 10 & 100 & 10 & 100 & 10 & 100 \\
\hline Stomach & No remarkable lesions & 10 & 100 & 10 & 100 & 10 & 100 & 10 & 100 \\
\hline Duodenum & No remarkable lesions & 10 & 100 & 10 & 100 & 10 & 100 & 10 & 100 \\
\hline Ileum & No remarkable lesions & 10 & 100 & 10 & 100 & 10 & 100 & 10 & 100 \\
\hline Jejunum & No remarkable lesions & 10 & 100 & 10 & 100 & 10 & 100 & 10 & 100 \\
\hline Cecum & No remarkable lesions & 10 & 100 & 10 & 100 & 10 & 100 & 10 & 100 \\
\hline Colon & No remarkable lesions & 10 & 100 & 10 & 100 & 10 & 100 & 10 & 100 \\
\hline Rectum & No remarkable lesions & 10 & 100 & 10 & 100 & 10 & 100 & 10 & 100 \\
\hline Skin & No remarkable lesions & 10 & 100 & 10 & 100 & 10 & 100 & 10 & 100 \\
\hline Mammary gland & No remarkable lesions & 10 & 100 & 10 & 100 & 10 & 100 & 10 & 100 \\
\hline Eye & No remarkable lesions & 10 & 100 & 10 & 100 & 10 & 100 & 10 & 100 \\
\hline Optic nerve & No remarkable lesions & 10 & 100 & 10 & 100 & 10 & 100 & 10 & 100 \\
\hline Harderian gland & No remarkable lesions & 10 & 100 & 10 & 100 & 10 & 100 & 10 & 100 \\
\hline Brain & No remarkable lesions & 10 & 100 & 10 & 100 & 10 & 100 & 10 & 100 \\
\hline \multirow[t]{2}{*}{ Pituitary } & No remarkable lesions & 10 & 100 & 10 & 100 & 9 & 90 & 10 & 100 \\
\hline & - Cyst, pars nervosa & 0 & 0 & 0 & 0 & 1 & 10 & 0 & 0 \\
\hline Femur & No remarkable lesions & 10 & 100 & 10 & 100 & 10 & 100 & 10 & 100 \\
\hline Spinal cord & No remarkable lesions & 10 & 100 & 10 & 100 & 10 & 100 & 10 & 100 \\
\hline Skeletal muscle & No remarkable lesions & 10 & 100 & 10 & 100 & 10 & 100 & 10 & 100 \\
\hline Sciatic nerve & No remarkable lesions & 10 & 100 & 10 & 100 & 10 & 100 & 10 & 100 \\
\hline Testis & No remarkable lesions & 10 & 100 & 10 & 100 & 0 & 0 & 0 & 0 \\
\hline Epididymis & No remarkable lesions & 10 & 100 & 10 & 100 & 0 & 0 & 0 & 0 \\
\hline Prostate & No remarkable lesions & 10 & 100 & 10 & 100 & 0 & 0 & 0 & 0 \\
\hline Seminal vesicle & No remarkable lesions & 10 & 100 & 10 & 100 & 0 & 0 & 0 & 0 \\
\hline Coagulating gland & No remarkable lesions & 10 & 100 & 10 & 100 & 0 & 0 & 0 & 0 \\
\hline Sternum & No remarkable lesions & 10 & 100 & 10 & 100 & 10 & 100 & 10 & 100 \\
\hline Ovary & No remarkable lesions & 0 & 0 & 0 & 0 & 10 & 100 & 10 & 100 \\
\hline Uterus & No remarkable lesions & 0 & 0 & 0 & 0 & 10 & 100 & 10 & 100 \\
\hline \multirow[t]{2}{*}{ Vagina } & No remarkable lesions & 0 & 0 & 0 & 0 & 9 & 90 & 10 & 100 \\
\hline & Epidermal cyst & 0 & 0 & 0 & 0 & 1 & 10 & 0 & 0 \\
\hline
\end{tabular}

$\mathrm{N}$ : Number of animals with the sign; SRE: water extract of Saposhnikoviae Radix. 
Table 8. Effects of SRE supplementation on body weight and liver, thymus, spleen, and kidney weights in PO-treated mice

\begin{tabular}{lcccccc}
\hline \hline & $\begin{array}{c}\text { Initial body } \\
\text { weight }(\mathrm{g})\end{array}$ & $\begin{array}{c}\text { Final body } \\
\text { weight }(\mathrm{g})\end{array}$ & $\begin{array}{c}\text { Liver } \\
\text { weight }(\mathrm{g})\end{array}$ & $\begin{array}{c}\text { Thymus } \\
\text { weight }(\mathrm{g})\end{array}$ & $\begin{array}{c}\text { Spleen } \\
\text { weight }(\mathrm{g})\end{array}$ & $\begin{array}{c}\text { Kidney } \\
\text { weight }(\mathrm{g})\end{array}$ \\
\hline Control & $30.82 \pm 0.33$ & $30.76 \pm 0.78$ & $1.70 \pm 0.072$ & $0.04 \pm 0.004$ & $0.09 \pm 0.005$ & $0.53 \pm 0.026$ \\
$\mathrm{PO}, 250 \mathrm{mg} / \mathrm{kg}$ & $30.88 \pm 0.82$ & $30.14 \pm 0.54$ & $0.53 \pm 0.019^{* * *}$ & $0.04 \pm 0.004$ & $0.08 \pm 0.003$ & $0.48 \pm 0.017$ \\
$\mathrm{PO}+125 \mathrm{mg} \mathrm{SRE} / \mathrm{kg}$ & $30.60 \pm 0.28$ & $28.56 \pm 0.57$ & $1.40 \pm 0.049^{*}$ & $0.04 \pm 0.005$ & $0.09 \pm 0.004$ & $0.46 \pm 0.010$ \\
PO + 250 mg SRE/kg & $31.84 \pm 0.38$ & $30.41 \pm 0.63$ & $1.64 \pm 0.061$ & $0.04 \pm 0.004$ & $0.09 \pm 0.006$ & $0.48 \pm 0.013$ \\
PO + 500 mg SRE/kg & $30.76 \pm 0.78$ & $31.60 \pm 0.86$ & $1.71 \pm 0.018$ & $0.04 \pm 0.007$ & $0.09 \pm 0.005$ & $0.49 \pm 0.022$ \\
PO + Allo, $5 \mathrm{mg} / \mathrm{kg}$ & $31.34 \pm 0.55$ & $31.30 \pm 0.90$ & $1.52 \pm 0.097^{*}$ & $0.03 \pm 0.002$ & $0.07 \pm 0.007$ & $0.48 \pm 0.025$ \\
PO + Benz, $10 \mathrm{mg} / \mathrm{kg}$ & $32.00 \pm 0.46$ & $29.62 \pm 0.36$ & $1.51 \pm 0.059^{*}$ & $0.04 \pm 0.005$ & $0.08 \pm 0.008$ & $0.48 \pm 0.018$ \\
\hline
\end{tabular}

Values represent mean \pm SD. Significantly different values from the control using Dunnett's test (two-tailed): ${ }^{*} p<0.05,{ }^{* *} p<0.01$ versus sex-matched control. Allo: allopurinol; Benz: benzbromarone; PO: potassium oxonate; and SRE: water extract of Saposhnikoviae Radix.

average $69 \%$ reduction of its mass. The SRE almost completely restored the PO-insulted liver weight loss; however, allopurinol and benzbromarone did not completely block the reduction of the liver mass.

- Effects of SRE supplementation on blood UA and creatinine in the PO-induced gout model in mice: When the UA level was determined as a total of serum and urine (Fig. 3A), PO insult highly increased the total level of UA, but this increase was markedly suppressed by supplementation with $\operatorname{SRE}(125,250$, and $500 \mathrm{mg} / \mathrm{kg} /$ day $)$. Allopurinol dramatically suppressed the total UA level, but benzbromarone was not effective at reducing the PO-induced increase in UA. It is assumed that a decrease in the total level of UA is associated with a decrease in XO activity. Thus, the effect of SRE supplementation on XO activity was measured using a commercial assay kit in mouse serum. Potassium oxonate insult caused an increase in XO activity, but this increase was suppressed by allopurinol treatment. The SRE supplementation suppressed XO activity, but its inhibitory effect was only significant at the dose of $500 \mathrm{mg} / \mathrm{kg}$ (Fig. 3B). These results suggest that decreased production of UA by SRE supplement is, at least in part, associated with its inhibitory effect on XO activity.

- Effect of SRE supplementation on changes of POinduced renal damage: UA-induced inflammation plays an important role in the progression of kidney injury (28). PO insult induced nuclear condensation and hyaline cast in the kidney, and these histological changes might be associated with the over 1.5 -fold increase observed in serum creatinine. This pathological transition of the kidney was markedly suppressed by supplementation of SRE. The antigout potential of SRE might be linked to its XO inhibitory effect, resulting in suppression of nuclear condensation and hyaline cast formation (Fig. 4).

Serum creatinine, which is used as a functional indicator for kidney function, was measured in the presence or absence of SRE in PO-insulted mice (Fig. 3C). Although total uric acid levels were significantly increased after PO insult (Fig. 3A), the serum levels of uric acid were not significantly reduced by SRE supplementation in the POtreated group. In contrast to previous reports $(29,30)$, it is unclear why serum levels of uric acid were not signifi-
(A)

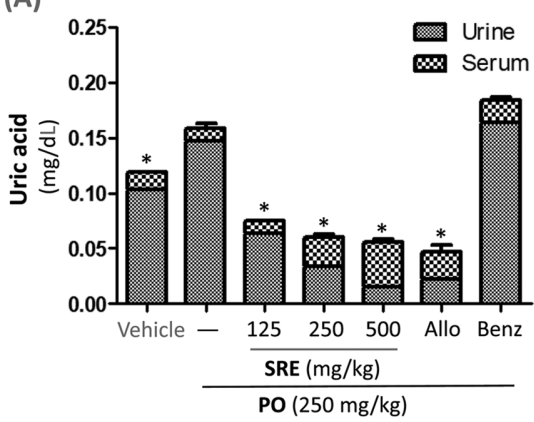

(B)

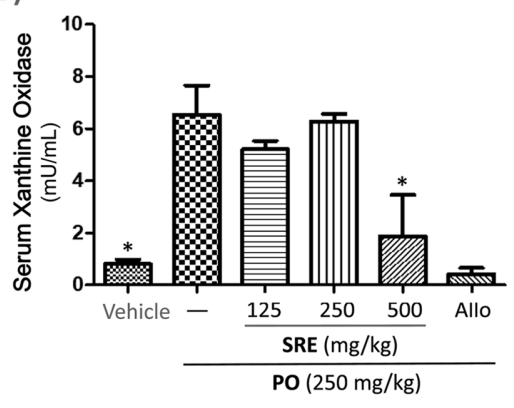

(C)

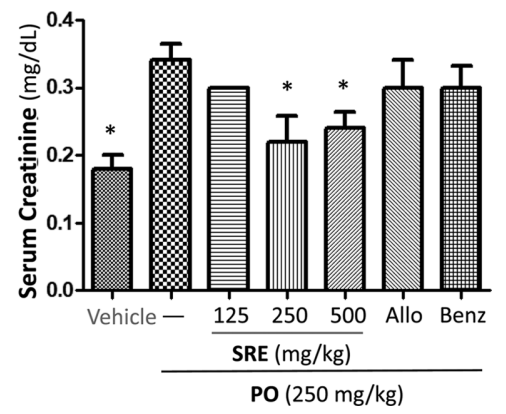

Fig. 3. Effect of SRE on uric acid, xanthine oxidase activity, and creatinine level in PO-insulted mice. Uric acid level in serum and urine was determined (A). Statistical differences were assessed for total level of uric acid. Xanthine oxidase activity was analyzed in the serum using commercial assay kit (Sigma-Aldrich) (B). Serum creatinine level (C) was determined by Hitachi 7180 (Hitachi). Allopurinol (Allo) was used as an XO inhibitor for the liver, and benzbromarone (Benz) was used as an inhibitor for uric acid transporter 1 in renal tubular cells. Values are presented as mean \pm SD. ${ }^{*} p<0.05$ versus only PO-treated group; PO, potassium oxonate; SRE, water extract of Radix Saposhnikoviae; XO, xanthine oxidase activity. 
Magnification, $\times 100$

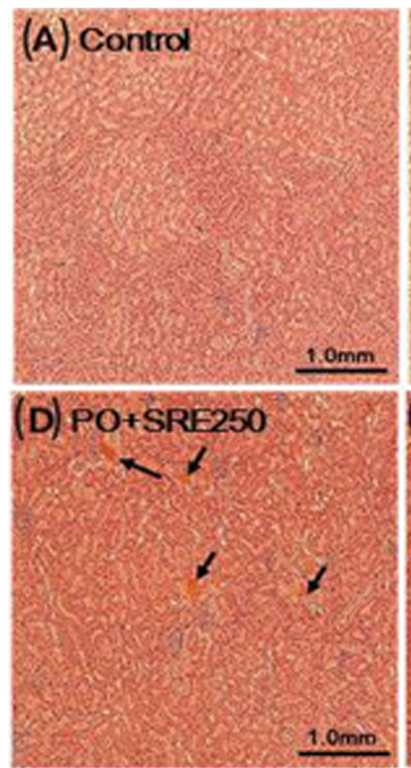

\section{Magnification, $\times 400$}
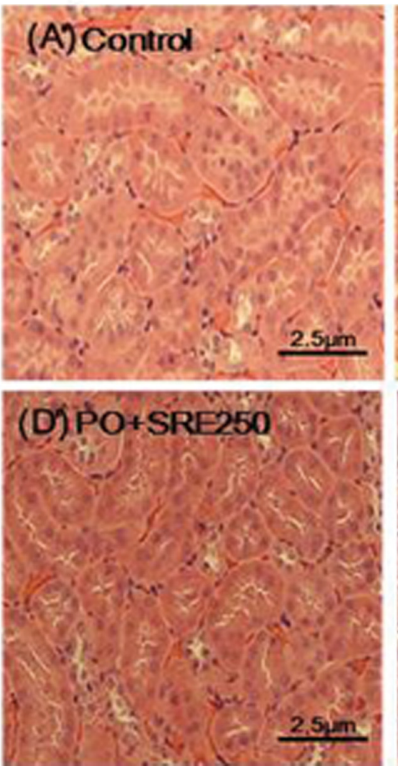
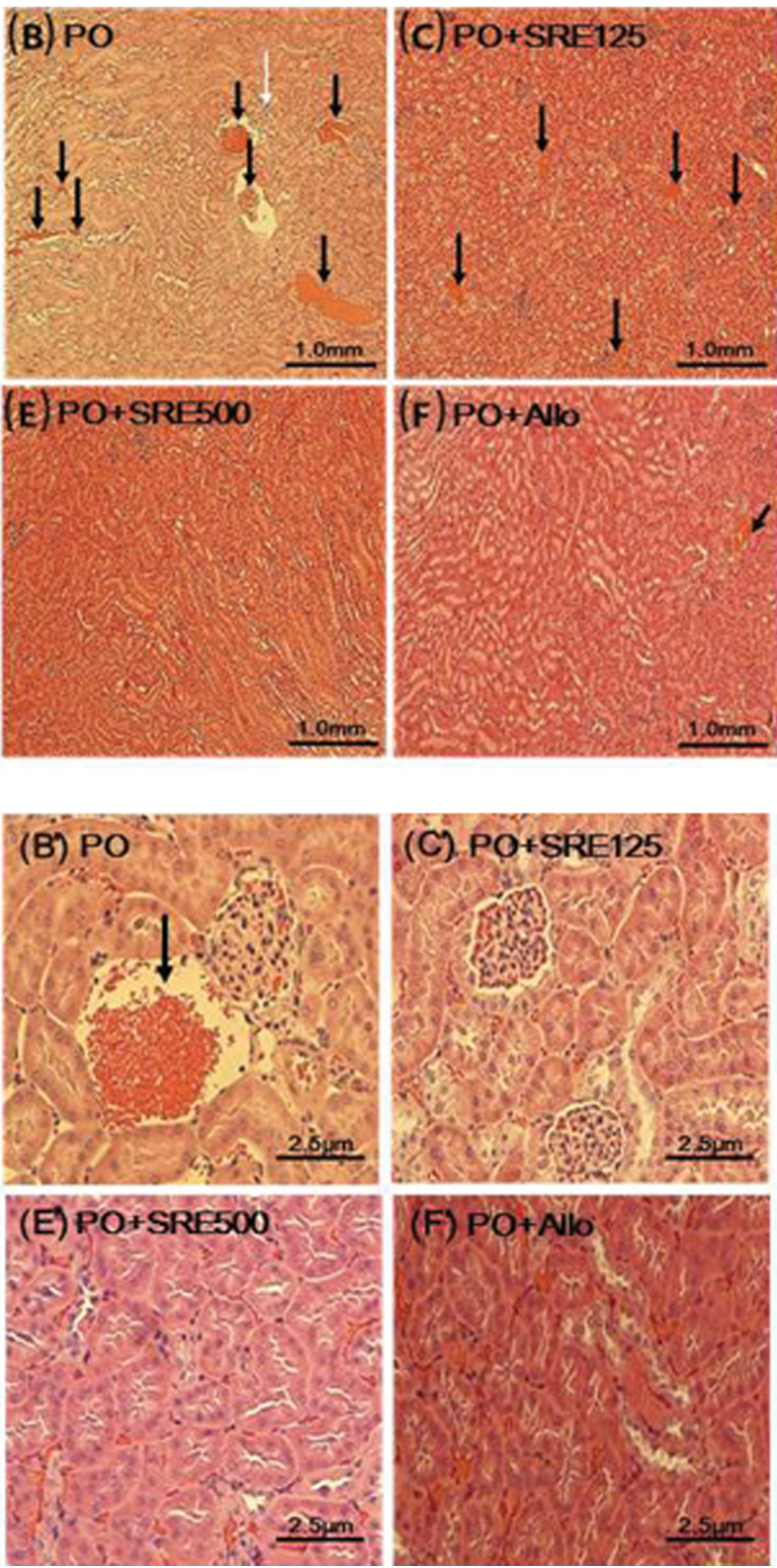

Fig. 4. Effect of SRE administration on the histology of the kidney. At the end of experiment, the histology of the kidney was analyzed after staining with hematoxylin and eosin. (A and A) untreated control. (B and B) PO-treated group. SRE was supplemented at a dose of 125 (C and C), 250 (D and D), and $500 \mathrm{mg} / \mathrm{kg}$. ( $E$ and $E$ ) in PO-treated mice. ( $F$ and F) allopurinol (5 mg/kg) in POtreated mice. White and black arrows indicate nuclear condensation and hyaline cast, respectively. Original magnifications of upper and lower images are $\times 100$ (upper panel; A-F) and $\times 400$ (lower panel; A'-F), respectively. PO, potassium oxonate; SRE, water extract of Saposhnikoviae Radix.

cantly increased even in the PO-treated group. Considering the fact that a significant increase in serum uric acid levels is seen several hours after PO administration (31), the late sampling time of blood conducted in our experiment may have resulted in the non-significant increase of uric acid. As shown in Fig. 4, the PO-treated group showed a marked presence of hyaline cast compared to the untreated control. This result may suggest that excessive contents of uric acid may have already accumulated in the kidney tissue as a cast, and thus relative serum levels of uric acid levels were not apparent. Regarding the POinduced histology of the kidney, there was a marked disappearance of the renal tubular epithelium and presence of nuclear condensation (karyopyknosis). This pathological 
change induced by PO insult was also markedly suppressed with the supplementation of SRE; thus, the changes in kidney structure might be associated with increased serum creatinine (Fig. 3C). Collectively, SRE supplementation suppressed XO activity and thereby suppressed the overproduction of UA in PO-insulted mice, helping maintain the pathology of the kidney. Excessive UA can cause renal damage and result in an increase in serum creatinine. However, supplementation of SRE attenuated the PO-induced pathological changes in the kidney through the suppression of excessive UA production.

\section{DISCUSSION}

Saposhnikoviae Radix (the root of Saposhnikovia divaricate) is an important traditional medicinal plant used in East Asia, including China and Japan. However, systemic toxicological evaluations have not been reported until now. In this experiment, acute, 4-week DRF, and 13-week subchronic toxicity evaluations of SRE were conducted on male and female rats. There were no significant toxicological outcomes of up to $5,000 \mathrm{mg} \mathrm{SRE} / \mathrm{kg} /$ day. Therefore, the oral SRE supplementation was safe up to $5,000 \mathrm{mg}$ $\mathrm{SRE} / \mathrm{kg} /$ day, and these data provide a basic toxicological assessment for future identification and development of SRE and its components as therapeutic agents. The SRE stored at $4^{\circ} \mathrm{C}$ was stable for up to one year based on the changes in nodakenin content. In the PO-induced mouse gout model, SRE supplementation suppressed hyperuricemia by inhibiting $\mathrm{XO}$ activity and thereby contributed to the blockage of UA-mediated kidney damage.

The 13-week toxicity study administering SRE to rats resulted in zero deaths. No behavioral alterations were recorded during the first half hour or at check-in points every six hours after the administration of SRE. Hence, the $\mathrm{LD}_{50}$ of SRE is thought to be greater than $5,000 \mathrm{mg} /$ $\mathrm{kg}$, and SRE can be considered non-toxic up to that dose. In 13-week subchronic toxicological evaluations of SRE up to $5,000 \mathrm{mg} / \mathrm{kg} /$ day, including changes in body weight (Table 1), food consumption rate (Table 2), urinalysis (Table 3), serum biochemistry (Table 4), hematology (Table 5), weight of organs (Table 6), and histopathology (Table 7), no meaningful toxicological outcomes were observed in either male or female SD rats (each group, $n=10$ ). In conjunction with no differences in food consumption rate, there were no significant changes in body weight gain (each group/sex, $\mathrm{n}=10$ ). A significant increase in total cholesterol and TG levels (Table 4) was observed at 500 and 1,000 $\mathrm{mg}$ of SRE in male rats without differences in food consumption rate (Table 2). However, this observation might be a result of random biological variation because these results were not found at the same dose in female rats and were also not found at higher doses of SRE in rats of either sex. To the best of our knowledge, there is no report indicating that SRE could cause increases in fat deposition. A decrease in total protein observed at 1,000 $\mathrm{mg} \mathrm{SRE} / \mathrm{kg} /$ day in male rats also appeared to be a result of random biological variation. In the urinalysis, no meaningful toxicological outcomes were observed at any given dose of SRE. Furthermore, no differences were seen in the weight of the spleen and thymus or blood composition, including red blood cells, hemoglobin, WBCs, platelets, among others. When evaluating changes in organ weight, there were no significant differences at any given dose of SRE except in the spleen and thymus; however, these changes seem to be normal variations because a dosedependent outcome was not observed and the changes were only seen in female rats. Moreover, pathological findings were not observed in the spleen or thymus (Table 7). In the pathological evaluation of the tissues, there were no meaningful outcomes suggesting toxicity of SRE (Table 7). Collectively, the SRE administration of up to $5000 \mathrm{mg} / \mathrm{kg}$ was safe. Considering that SRE is a mixture of various compounds present in Saposhnikoviae Radix, isolated individual active compounds from SRE and mixtures thereof are likely safe in doses up to the equivalent of that in $5,000 \mathrm{mg}$ SRE. It should be noted that the toxicological outcomes of SRE presented in this experiment are based on the conditions of a normal chow diet with SRE supplementation; thus, toxicological side effects of SRE cannot be completely excluded due to the absence of evidence regarding interactions with classical synthetic drugs and/or foods such as grapefruit juice, which can modify the absorption, distribution, metabolism, and/or excretion processes (32).

Gout is a common form of inflammatory arthritis caused by excessive deposition of monosodium urate, resulting in pain, damage, and deformity of joints. Gout incidence (0.3-6 per 1000 person-years) and prevalence (1-10\%) have been increasing (33) and are becoming important health burdens worldwide. Chronic hyperuricemia is the main precursor of gout; thus, inhibition of XO overactivation is a promising therapeutic option to limit the harmful effects of excess UA (27). Traditionally, Saposhnikoviae Radix is called "Bang Fung" in Korea and "Fang-Feng" in China, which means "to prevent gout." However, the scientific evaluation of SRE against gout has not been well established. The SRE supplementation at 500 and 1,000 $\mathrm{mg} / \mathrm{kg} /$ day for 13 weeks significantly lowered serum UA in male rats but not female rats (Table 4). There were no significant toxicological manifestations in the subchronic 13-week repeated-dose toxicity of SRE. Therefore, the antihyperuricemic potential of SRE was investigated in this study on PO-insulted mice model. Hyperuricemia is an underlying condition of gout, and long-term treatment of gout almost always involves the therapeutic lowering of serum urate level through the use of XO inhibitors (e.g., febuxostat), enhancing the degradation and inhibition of 
urate reuptake in the kidney (34). Furthermore, anti-inflammatory strategies targeting interleukin- 1 beta (IL-1 $\beta$ ) have been explored recently (34). However, safety concerns about medications treating acute and chronic gout are still present (35). In addition to toxicological evaluations of SRE, the present study provides evidence, using a POmediated experimental mice model, for the therapeutic potential of SRE against hyperuricemia and gout. Potassium oxonate blocks the effects of hepatic uricase that produce hyperuricemia in mice (18) and thus was used as a model system for investigating nephropathy and other toxicity evaluations connected with excess UA (19). The supplementation of SRE suppressed the production of UA in serum and urine (Fig. 3A). This reduction of UA by SRE supplementation was associated with its inhibitory action on XO (Fig. 3B). High levels of serum UA can cause kidney disease and secondary hypertension (36). Allopurinol is a specific inhibitor of xanthine oxidase, which is the key enzyme for the metabolism of purine nucleotides to uric acid. Serum creatinine levels reflect the malfunction of the kidney and are not directly affected by xanthine oxidase activity. Thus, it seems that the serum creatinine levels were not significantly reduced by allopurinol despite xanthine oxidase inhibition by allopurinol (Fig. 3B). This result may indicate that SRE supplementation may exhibit dual effects: suppression of uric acid production and protection against secondary renal damage caused by excessive uric acid.

It should be mentioned that oxonic acid is not an ideal uricase inhibitor because oxonic acid and its salts are foreign substances that could interfere with other metabolic systems (19). In general, the reduction of body or organ weight indicates that a certain substance has toxicity or is metabolized into another toxic substance. It is unclear whether a significant decrease in the liver weight of POtreated mice was associated with its interference with the metabolic system(s) and/or its toxic effects in the liver. However, the supplementation of SRE was able to attenuate the weight loss of the liver (Table 8).

Collectively, SRE did not display acute, 4-week DRF, and 13 -week subchronic toxicity of up to $5,000 \mathrm{mg} / \mathrm{kg}$ based on toxicological parameters. The SRE showed antihyperuricemic effects via the inhibition of XO activity, suppressing PO-induced pathological changes including nuclear condensation and hyaline cast formation in the kidney. To the best of our knowledge, this is the first toxicological and safety evaluation of SRE, and the results support its therapeutic potential against hyperuricemia in rodents in accordance with its traditional use.

The SRE was safe up to $5,000 \mathrm{mg} / \mathrm{kg} /$ day based on NOAEL found in acute and 13-week subchronic toxicological evaluations. Furthermore, SRE showed antihyperuricemic effects and lowered the excessive level of uric acid, which is associated with gout and kidney failure.

\section{ACKNOWLEDGMENTS}

This work was supported by a grant from the Ministry of Food and Drug Safety, South Korea, in 2016 (15182MFDS452).

\section{CONFLICT OF INTEREST}

There are no conflicts to declare.

Received November 6, 2018; Revised February 8, 2019; Accepted March 5, 2019

\section{REFERENCES}

1. WHO (2013) WHO traditional medicine strategy: 20142023.

2. Fan, T.P., Deal, G., Koo, H.L., Rees, D., Sun, H., Chen, S., Dou, J.H., Makarov, V.G., Pozharitskaya, O.N., Shikov, A.N., Kim, Y.S., Huang, Y.T., Chang, Y.S., Jia, W., Dias, A., Wong, V.C. and Chan, K. (2012) Future development of global regulations of Chinese herbal products. J. Ethnopharmacol., 140, 568-586.

3. Kreiner, J., Pang, E., Lenon, G.B. and Yang, A.W.H. (2017) Saposhnikoviae divaricata: a phytochemical, pharmacological, and pharmacokinetic review. Chin. J. Nat. Med., 15, 255-264.

4. Liu, R., Wu, S. and Sun, A. (2008) Separation and purification of four chromones from radix saposhnikoviae by highspeed counter-current chromatography. Phytochem. Anal., 19, 206-211.

5. Wang, C.N., Shiao, Y.J., Kuo, Y.H., Chen, C.C. and Lin, Y.L. (2000) Inducible nitric oxide synthase inhibitors from Saposhnikovia divaricata and Panax quinquefolium. Planta Med., 66, 644-647.

6. Okuyama, E., Hasegawa, T., Matsushita, T., Fujimoto, H., Ishibashi, M. and Yamazaki, M. (2001) Analgesic components of saposhnikovia root (Saposhnikovia divaricata). Chem. Pharm. Bull., 49, 154-160.

7. Tai, J. and Cheung, S. (2007) Anti-proliferative and antioxidant activities of Saposhnikovia divaricata. Oncol. Rep., 18, 227-234.

8. Liao, H., Li, Q., Liu, R., Liu, J. and Bi, K. (2014) Fingerprint analysis and multi-ingredient determination using a single reference standard for saposhnikoviae radix. Anal. Sci., 30, 1157-1163.

9. Kim, M.K., Yang, D.H., Jung, M., Jung, E.H., Eom, H.Y., Suh, J.H., Min, J.W., Kim, U., Min, H., Kim, J. and Han, S.B. (2011) Simultaneous determination of chromones and coumarins in Radix Saposhnikoviae by high performance liquid chromatography with diode array and tandem mass detectors. J. Chromatogr. A, 1218, 6319-6330.

10. Rim, H.K., Cho, W., Sung, S.H. and Lee, K.T. (2012) Nodakenin suppresses lipopolysaccharide-induced inflammatory responses in macrophage cells by inhibiting tumor necrosis factor receptor-associated factor 6 and nuclear factor-kap$\mathrm{paB}$ pathways and protects mice from lethal endotoxin shock. J. Pharmacol. Exp. Ther., 342, 654-664. 
11. Jameel, E., Umar, T., Kumar, J. and Hoda, N. (2016) Coumarin: a privileged scaffold for the design and development of antineurodegenerative agents. Chem. Biol. Drug Des., 87, 21-38.

12. Lee, H., Lee, J.K., Ha, H., Lee, M.Y., Seo, C.S. and Shin, H.K. (2012) Angelicae dahuricae radix inhibits dust mite extract-induced atopic dermatitis-like skin lesions in $\mathrm{NC} /$ Nga mice. Evid. Based Complement. Alternat. Med., 2012, 743075 .

13. Kim, S.J., Ko, S.M., Choi, E.J., Ham, S.H., Kwon, Y.D., Lee, Y.B. and Cho, H.Y. (2018) Simultaneous determination of decursin, decursinol angelate, nodakenin, and decursinol of angelica gigas nakai in human plasma by UHPLC-MS/ MS: application to pharmacokinetic study. Molecules, 23.

14. Calil Brondani, J., Reginato, F.Z., da Silva Brum, E., de Souza Vencato, M., Lima Lhamas, C., Viana Silva, C., da Rocha, M.I., de Freitas Bauermann, L. and Manfron, M.P. (2017) Evaluation of acute and subacute toxicity of hydroethanolic extract of Dolichandra unguis-cati L. leaves in rats. $J$. Ethnopharmacol., 202, 147-153.

15. Park, M.-Y., Choi, H.-Y., Kim, J.-D., Lee, H.-S. and Ku, S.-K. (2010) 28 Days repeated oral dose toxicity test of aqueous extracts of mahwangyounpae-tang, a polyherbal formula. Food Chem. Toxicol., 48, 2477-2482.

16. Wills, R.B., Bone, K. and Morgan, M. (2000) Herbal products: active constituents, modes of action and quality control. Nutr. Res. Rev., 13, 47-77.

17. Kuo, C.F., Grainge, M.J., Mallen, C., Zhang, W. and Doherty, M. (2015) Rising burden of gout in the UK but continuing suboptimal management: a nationwide population study. Ann. Rheum. Dis., 74, 661-667.

18. Sarvaiya, V.N., Sadariya, K.A., Pancha, P.G., Thaker, A.M., Patel, A.C. and Prajapati, A.S. (2015) Evaluation of antigout activity of Phyllanthus emblica fruit extracts on potassium oxonate-induced gout rat model. Vet. World, 8, 12301236.

19. Stavric, B. and Nera, E.A. (1978) Use of the uricase-inhibited rat as an animal model in toxicology. Clin. Toxicol., 13, 47-74.

20. Hall, B.G. (2013) Building phylogenetic trees from molecular data with MEGA. Mol. Biol. Evol., 30, 1229-1235.

21. Slabbinck, B., Dawyndt, P., Martens, M., De Vos, P. and De Baets, B. (2008) TaxonGap: a visualization tool for intraand inter-species variation among individual biomarkers. Bioinformatics, 24, 866-867.

22. Seo, U.M., Zhao, B.T., Kim, Y.H., Kang, J.S., Son, J.K. and Woo, M.H. (2016) Simultaneous analysis of seven marker compounds from Saposhnikoviae Radix, Glehniae Radix and Peucedani Japonici Radix by HPLC/PDA. Arch. Pharm. Res., 39, 695-704.

23. Seo, C.-S. and Shin, H.-K. (2015) Simultaneous determination of nine marker compounds in the traditional Korean medicine, Dangguisu san by high performance liquid chromatography. Pharmacogn. Mag., 11, 555-561.

24. Mumford, S.L., Dasharathy, S.S., Pollack, A.Z., Perkins, N.J., Mattison, D.R., Cole, S.R., Wactawski-Wende, J. and Schisterman, E.F. (2013) Serum uric acid in relation to endogenous reproductive hormones during the menstrual cycle: findings from the BioCycle study. Hum. Reprod., 28, 1853-1862.

25. Nguyen, M.T., Awale, S., Tezuka, Y., Tran, Q.L., Watanabe, H. and Kadota, S. (2004) Xanthine oxidase inhibitory activity of Vietnamese medicinal plants. Biol. Pharm. Bull., 27, 1414-1421.

26. Thakur, L., Ghodasra, U., Patel, N. and Dabhi, M. (2011) Novel approaches for stability improvement in natural medicines. Pharmacogn. Rev., 5, 48-54.

27. Bove, M., Cicero, A.F., Veronesi, M. and Borghi, C. (2017) An evidence-based review on urate-lowering treatments: implications for optimal treatment of chronic hyperuricemia. Vasc. Health Risk Manag., 13, 23-28.

28. Wang, M.X., Liu, Y.L., Yang, Y., Zhang, D.M. and Kong, L.D. (2015) Nuciferine restores potassium oxonate-induced hyperuricemia and kidney inflammation in mice. Eur. $J$. Pharmacol., 747, 59-70.

29. Chen, G., Tan, M.L., Li, K.K., Leung, P.C. and Ko, C.H. (2015) Green tea polyphenols decreases uric acid level through xanthine oxidase and renal urate transporters in hyperuricemic mice. J. Ethnopharmacol., 175, 14-20.

30. Dolati, K., Rakhshandeh, H., Golestani, M., Forouzanfar, F., Sadeghnia, R. and Sadeghnia, H.R. (2018) Inhibitory effects of apium graveolens on xanthine oxidase activity and serum uric acid levels in hyperuricemic mice. Prev. Nutr. Food Sci., 23, 127-133.

31. Tung, Y.T., Lin, L.C., Liu, Y.L., Ho, S.T., Lin, C.Y., Chuang, H.L., Chiu, C.C., Huang, C.C. and Wu, J.H. (2015) Antioxidative phytochemicals from Rhododendron oldhamii Maxim. leaf extracts reduce serum uric acid levels in potassium oxonate-induced hyperuricemic mice. BMC Complement. Altern. Med., 15, 423.

32. Margina, D., Ilie, M., Gradinaru, D., Androutsopoulos, V.P., Kouretas, D. and Tsatsakis, A.M. (2015) Natural productsfriends or foes? Toxicol. Lett., 236, 154-167.

33. Kuo, C.F., Grainge, M.J., Zhang, W. and Doherty, M. (2015) Global epidemiology of gout: prevalence, incidence and risk factors. Nat. Rev. Rheumatol., 11, 649-662.

34. Igel, T.F., Krasnokutsky, S. and Pillinger, M.H. (2017) Recent advances in understanding and managing gout. F1000Res, 6 , 247.

35. Schlesinger, N. (2017) The safety of treatment options available for gout. Expert Opin. Drug Saf., 16, 429-436.

36. Ohno, I. (2011) Relationship between hyperuricemia and chronic kidney disease. Nucleosides Nucleotides Nucleic Acids, 30, 1039-1044. 